This item was submitted to Loughborough's Research Repository by the author.

Items in Figshare are protected by copyright, with all rights reserved, unless otherwise indicated.

\title{
Fracture mechanics and damage mechanics based fatigue lifetime prediction of adhesively bonded joints subjected to variable amplitude fatigue
}

\section{PLEASE CITE THE PUBLISHED VERSION}

http://dx.doi.org/10.1016/j.engfracmech.2010.03.008

\section{PUBLISHER}

(c) Elsevier

VERSION

AM (Accepted Manuscript)

\section{LICENCE}

CC BY-NC-ND 4.0

\section{REPOSITORY RECORD}

Shenoy, Vikram, lan A. Ashcroft, Gary W. Critchlow, and A.D. Crocombe. 2012. "Fracture Mechanics and Damage Mechanics Based Fatigue Lifetime Prediction of Adhesively Bonded Joints Subjected to Variable Amplitude Fatigue". figshare. https://hdl.handle.net/2134/9623. 
This item was submitted to Loughborough's Institutional Repository (https://dspace.lboro.ac.uk/) by the author and is made available under the following Creative Commons Licence conditions.

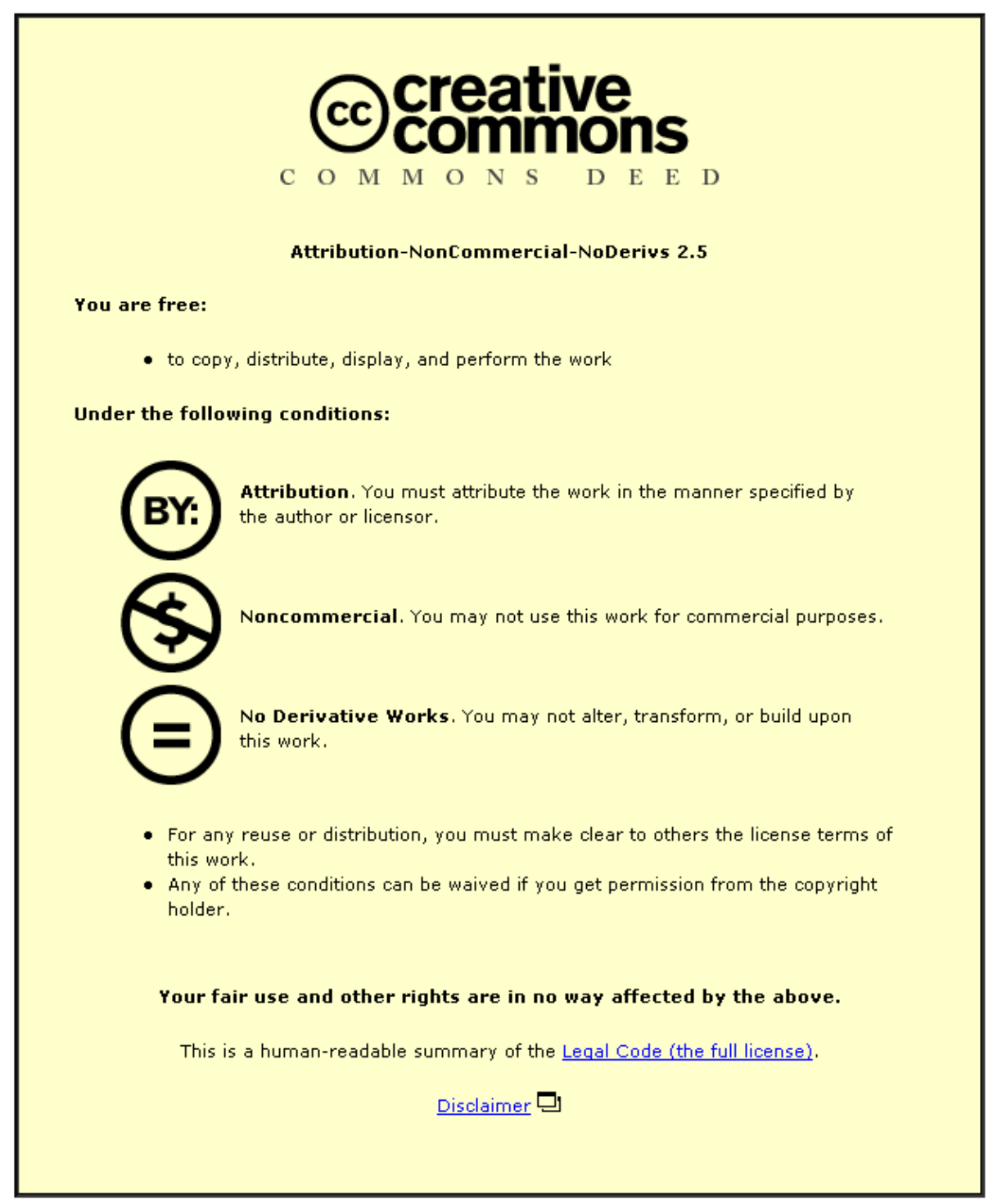

For the full text of this licence, please go to: http://creativecommons.org/licenses/by-nc-nd/2.5/ 
Elsevier Editorial System(tm) for Engineering Fracture Mechanics Manuscript Draft

Manuscript Number:

Title: Fracture mechanics and damage mechanics based fatigue lifetime prediction of adhesively bonded joints subjected to variable amplitude fatigue.

Article Type: Research Paper

Keywords: Variable amplitude fatigue; bonded joints; fracture mechanics; damage mechanics.

Corresponding Author: Dr. lan Ashcroft,

Corresponding Author's Institution: Loughborough University

First Author: Ian Ashcroft

Order of Authors: Ian Ashcroft; Vikram Shenoy; Gary Critchlow; Andy Crocombe

Abstract: The first part of the paper describes an investigation into the behaviour of adhesively bonded single lap joints (SLJs) subjected to various types of variable amplitude fatigue (VAF) loading. It was seen that a small proportion of fatigue cycles at higher fatigue loads could result in a significant reduction in the fatigue life. Pamgren-Miner's damage sum tended to be less than 1 , indicating damage accelerative loadd interaction effects. In the second part of the paper, fracture mechanics (FM) and damage mechanics (DM) approaches are used to predict the fatigue lifetime for these joints. Two FM based approaches were investigated, which differed with respect to the cycle counting procedure, however, both approaches were found to under- predict the fatigue lifetime for all the types of spectra used. This was attributed to the inability of the FM based models to simulate the crack initiation phase. A DM based approach was then used with a power law relationship between equivalent plastic strain and the damage rate. Good predictions were found for most of the spectra, with a tendency to over-predict the fatigue life. 



\title{
Fracture mechanics and damage mechanics based fatigue lifetime prediction of adhesively bonded joints subjected to variable amplitude fatigue.
}

\author{
V. Shenoy ${ }^{\text {a }}$ I. A. Ashcroft ${ }^{\text {a }}$, G. W. Critchlow ${ }^{\text {b }}$, \\ A. D. Crocombe ${ }^{\mathrm{c}}$. \\ ${ }^{a}$ Wolfson School of Mechanical and Manufacturing Engineering, \\ Loughborough University, LE11 3TU, UK. \\ ${ }^{b}$ Department of Materials, \\ Loughborough University, LE11 3TU, UK. \\ ${ }^{c}$ Faculty of Engineering and Physical Sciences, University of Surrey, \\ Guildford, Surrey, GU2 5XH, UK.
}

\begin{abstract}
The first part of the paper describes an investigation into the behaviour of adhesively bonded single lap joints (SLJs) subjected to various types of variable amplitude fatigue (VAF) loading. It was seen that a small proportion of fatigue cycles at higher fatigue loads could result in a significant reduction in the fatigue life. Pamgren-Miner's damage sum tended to be less than 1, indicating damage accelerative loadd interaction effects. In the second part of the paper, fracture mechanics (FM) and damage mechanics (DM) approaches are used to predict the fatigue lifetime for these joints. Two FM based approaches were investigated, which differed with respect to the cycle counting procedure, however, both approaches were found to under- predict the fatigue lifetime for all the types of spectra used. This was attributed to the inability of the FM based models to simulate the crack initiation phase. A DM based approach was then used with a power law relationship between equivalent plastic strain and the damage rate. Good predictions were found for most of the spectra, with a tendency to over-predict the fatigue life.
\end{abstract}

Keywords: Variable amplitude fatigue, bonded joints, fracture mechanics, damage mechanics. 


\subsection{Introduction}

In many applications adhesively bonded joints are being considered as replacements for conventional joining techniques, such as bolted or riveted joints, owing to their numerous advantages, including; high stiffness, good strength-to-weight ratio, ability to join dissimilar materials and more uniform stress distribution. However, certain disadvantages are also associated with adhesive bonding, such as; limited operating range, environmental sensitivity and difficulty of disassembly. In structural applications, fatigue is generally considered to be the most important form of loading in respect to long-term service life and, hence, the effect of fatigue on structural adhesive joints has been extensively studied [1-10]. Most of this work has involved constant amplitude sinusoidal fatigue. However, recent work has indicated that fatigue induced degradation of bonded joints is accelerated when overloads and mean load changes are incorporated into the fatigue spectrum [11-14], thus, predictive methods based on constant amplitude fatigue (CAF) data for bonded joints will tend to be non-conservative. As most bonded joints in structural applications are subjected to variable amplitude fatigue (VAF), this effect requires further investigation and the development of life-prediction methods that take into account any VAF induced damage acceleration effects.

Behaviour under VAF has been studied by many authors, especially for metals and composites. One of the earliest studies by Palmgren [15], showed a decrease in fatigue life for ball bearings under multistage block loading. One of the main types of VAF spectra investigated consists of overloads introduced after a certain number of constant amplitude cycles. Most of the previous studies in metals have shown crack growth retardation after overloads [16-18]; this is because of the formation of increased plastic zones ahead of the crack tip after overloads. However, crack growth accelerations have been seen in brittle metals [16-17, 19] and composites [18] subjected to overloads. Less work has been published on the effect of mean load changes, however, Schaff and Davidson [20-21], associated mean load changes with 
accelerated strength wearout in composites. In the case of bonded joints, studies have reported an accelerated failure for both mean load changes $[11,13]$ and overloads $[10,12]$.

Fatigue lifetime predictive methods for VAF can be categorised into three groups, namely; PalmgrenMiner (PM) based models, phenomenological models and progressive damage models. In the original PM model $[15,22]$, an assumption of linear fatigue damage accumulation is made. Damage for a block loaded VAF spectrum is calculated as:

$$
\mathrm{D}_{\mathrm{PM}}=\sum_{\mathrm{i}=1}^{\mathrm{n}_{\mathrm{b}}} \frac{\mathrm{n}}{\mathrm{N}_{\mathrm{f}}}
$$

where, $\mathrm{n}$ is the applied cycles in a block, $\mathrm{N}_{\mathrm{f}}$ is the number of cycles to failure under CAF loading for the fatigue load in this block and $n_{b}$ is the number of blocks. The damage calculated for different blocks is then added linearly. When the damage sum, $\mathrm{D}_{\mathrm{PM}}$, is equal to 1 , the specimen is assumed to fail. In this method any interaction effects responsible for crack growth acceleration or deceleration are not considered. Hence an over-prediction will be seen when the fatigue lifetime undergoes crack growth accelerations and an under prediction when the lifetime has crack growth deceleration. The basic PM rule has been extended by a number of researchers. For example, Marco and Starkley [23], incorporated nonlinear effects by defining damage with a power law type of relationship. However, the basic weakness of the method, that there is no physical basis for the assumed damage accumulation, remains in the various extensions to the PM method.

In the phenomenological models, phenomena such as strength or stiffness are used as a measure of increasing damage during fatigue loading. These models have mostly been applied to CAF. For example, Hahn and Kim [24-25] and Hwang and Hahn [26] proposed the prediction of fatigue life by assuming a linear degradation of the residual strength. In the work of Shaff and Davidson [20-21] a non-linear strength wearout was assumed, however, the strength wearout was only indirectly related to fatigue damage. In this work, they used the strength based wearout model for composite materials to predict 
fatigue lifetime for spectrum loading. In their model, they used a cycle mix parameter to incorporate the effects of mean load jumps introduced in the spectrum loading. A similar method was applied to bonded composite joints by Erpolat et al [11]. In this case, however, the strength wearout was assumed to be linear and lifetime was predicted using a linear cycle mix model for various VAF loading spectra. Erpolat et al [11] also demonstrated the inadequacy of the PM rule to accurately predict the fatigue lifetime of bonded single lap joints.

In fracture mechanics (FM) based progressive damage modelling approaches to fatigue lifetime prediction, the crack growth rate is normally related to the stress intensity factor [27] or strain energy release rate $[1-3,8,10,12]$. However, Elber [28] argued that crack closure effects may be responsible for at least part of the interaction effect observed between stress levels in the fatigue testing of metals. This was implemented by Newman [29], who accounted for crack closure effects and predicted lifetime under VAF using an effective stress intensity factor. In the case of bonded joints, a damage shift parameter has been proposed to account for accelerative interaction effects $[10,12]$. Important interaction effects considered here were crack growth acceleration associated with mean load changes and overloads. However, the FM approaches only consider the crack propagation phase of fatigue and if the initiation phase in the fatigue lifetime is dominant, FM based laws may under-predict the fatigue life. A damage mechanics (DM) approach is better suited to such cases. In this method, a damage evolution law is defined that characterises pre-cracking damage evolution in addition to crack growth. In the case of bonded joints, there is little work published in this field. However, Abdel Wahab et al [30] compared both FM and DM approaches to the fatigue lifetime prediction of bonded CFRP double lap joints. They demonstrated that the proposed DM method compared favourably with a FM approach in the case of CAF, however, they did not study VAF.

In summary, it can be seen that there is ample evidence to show that damage or crack growth accelerations or decelerations can occur under VAF loading due to load interaction effects, and that this is dependent on the type of material. To date, little work has been published on the effect of VAF on 
adhesively bonded joints. In the first part of this paper, different types of VAF spectra are used to study the effect of load interactions on the fatigue lifetime of bonded SLJs. This is a continuation of the work conducted by Erpolat et al. [10], however, a more comprehensive range of VAF spectra are considered. In the second part of the paper, both FM and DM based approaches to predicting VAF lifetime are investigated. The FM based method is based on numerical crack growth integration (NCGI), as already discussed in $[10,12]$. The DM based approach consists of a damage evolution law, which is applied to the VAF of bonded joints for the first time in this paper.

\subsection{Experimental}

\subsection{Materials and joint preparation}

Single lap joints (SLJs) were prepared to the dimensions specified in British standard BS (4567:2003), as shown in Fig. 1 (a). The adherends were cut from 2.5mm thick sheets of Clad 7075-T6 aluminium alloy. The adhesive used was the toughened epoxy film adhesive FM 73M, supplied by Cytec Engineered Materials, Arizona, USA, with film thickness of $0.2 \mathrm{~mm}$.

The adherends were ultrasonically cleaned in an acetone bath for five minutes prior to pre-treatment using a patented alternating current, direct current (ACDC) anodisation process [31]. This treatment is proposed as an environmentally friendly alternative to current chromate containing processes. The adherend to be treated is one of the electrodes in an electrochemical cell. A mixture of phosphoric (2.5\%) and sulphuric acid $(2.5 \%)$ is used as the electrolyte and the other electrode is titanium. An alternating current (AC) is ramped up to $15 \mathrm{~V}$ over a period of 1 minute and then kept at this voltage for two more minutes. The current is changed to direct current (DC), increased to $20 \mathrm{~V}$ and kept at this voltage for 10 minutes. The adherends are then washed with distilled water and dried in hot air.

After the ACDC pre-treatment, a thin film of BR 127 corrosion resistant primer, manufactured by Cytec Engineered Materials Ltd., was applied to the aluminium adherends. This was dried at room temperature 
and then cured at $120^{\circ} \mathrm{C}$ for half an hour. The adherends were returned to room temperature before bonding. The FM 73M adhesive was taken from freezer storage and brought to room temperature in a dry atmosphere before bonding. The adhesive was cured at $120^{\circ} \mathrm{C}$ for one hour, with constant pressure applied through clips. No attempt was made to control the fillet geometry but owing to the accurate cutting of the film adhesive, the natural fillets formed were fairly small and uniform between samples. The bonded joints were stored in a dessicator at room temperature prior to testing.

Compound double cantilever beams (CDCB) were used to generate fracture mechanics data in order to avoid the plastic deformation seen when testing double cantilever beams (DCBs) made from the unreinforced aluminium alloy sheet used in this work. The procedures proposed by Blackman and Kinloch [32] were generally followed in the testing of the CDCBs in this work. Fig. 1 (b) shows the dimensions of the CDCBs.

A procedure recommended in Adams et al. [33] was used for pre-treating the mild steel adherends used in the CDCBs. Any rust or mill scale was first removed using a clean wire brush and the samples vapour degreased to remove any oil from the surface. The surface was grit-blasted to make the surface more even and to remove any remaining rust. The specimens were then etched for $10 \mathrm{~min}$ at $71-77^{\circ} \mathrm{C}$, in an etching solution consisting of sodium dichromate (10\%), sulphuric acid $(22 \%)$ and water $(68 \%)$. After the specimens were etched, they were washed in a running stream of water and carbon residues were removed using a Nylon brush. The surface was then washed with distilled water followed by a bath of acetone and finally dried at $93^{\circ} \mathrm{C}$ using an air dryer. BR 127 primer was applied to the surfaces to be bonded, as described previously, before storing the specimens in a desiccator.

The CDCBs were prepared by firstly manufacturing 7075 T6-FM73 DCBs and then retrofitting the DCBs with mild steel reinforcing adherends to make the CDCBs. A PTFE film was placed between the 7075 T6 adherends to create a pre-crack, as shown in Fig. 1 (b). Extra bolted retrofittings were used to join the steel to the aluminium at both ends in order to prevent crack initiation in the adhesive between the steel 
and the aluminium adherends. The joints used for fatigue testing were fitted with crack gauges supplied by Rumul $\mathrm{GmbH}$, for crack growth monitoring. Before bonding the crack gauges to the CDCBs, any adhesive spew at the edges of the joint was removed to make an even surface. M-Bond adhesive, provided by Vishay Instruments Plc., was used for bonding the gauges to the CDCBs. Electrical wires were soldered onto the gauges and connected to insulator bases, mounted on the mild steel adherends. Lead wires from the insulator bases were then connected to the "Fractomat" (supplied by Rumul GmbH), a conditioner for the crack gauge signals.

\subsection{Quasi-static and constant amplitude fatigue (CAF) testing}

The quasi-static and CAF results for the SLJs have been reported previously [34-35] but are summarised here as they are required for the predictive methodologies reported in Section 4. These references should be used if further details of the testing procedures or interpretation of results are required. All tests were carried out under ambient laboratory environmental conditions, in which temperature ranged from 22$25^{\circ} \mathrm{C}$ and relative humidity ranged from $35-40 \%$ during the tests. An Instron 6024 servo-hydraulic testing machine from Instron Ltd, Bucks, UK, was used for all the testing. The CDCBs and SLJs were tested quasi-statically using an Instron 6024 servo hydraulic testing machine with a constant displacement rate of $0.1 \mathrm{~mm} / \mathrm{min}$. The edges of the CDCBs were polished and painted with white correction fluid in order to facilitate the monitoring of crack growth during the test.

The SLJs were fatigue tested in load control using a sinusoidal waveform with a load ratio of 0.1 and frequency of $5 \mathrm{~Hz}$. Various percentages of the quasi-static failure load (QSFL) were taken as the maximum load in the fatigue spectrum. CDCBs were fatigue tested in displacement control, with a displacement ratio of 0.1 and frequency of 5Hz. Crack gauges were mounted on the edges of the CDCBs in order to measure crack growth during testing.

2.3 Variable amplitude fatigue (VAF) testing 
VAF loading is divided in this work into five groups. In the first group, shown in Fig. 2 (a), load amplitude $\left(\mathrm{L}_{\mathrm{a}}\right)$ and mean load $\left(\mathrm{L}_{\text {mean }}\right)$ were varied and the load ratio $(\mathrm{R})$ was kept constant for the two stages in the loading spectrum. This enabled the effect of changing the maximum load, whilst maintaining a constant R-ratio to be investigated. This had the advantage that the effect of load interaction could be studied using the PM rule with the CAF data generated with $\mathrm{R}=0.1$. As shown in Fig. 2(a), a constant amplitude block of $\mathrm{n}_{1}$ cycles with a mean load of $\mathrm{L}_{\text {mean } 1}$ and maximum load of $\mathrm{L}_{\max 1}$ is alternated with a block of $n_{2}$ cycles with mean and maximum loads of $\mathrm{L}_{\text {mean2 } 2}$ and $\mathrm{L}_{\max 2}$ respectively. Two variants of this type of spectra were investigated, as characterised by different values of $n_{1}$ and $n_{2}$. In Type A spectra $\mathrm{n}_{1}=10$ and $\mathrm{n}_{2}=5$ whereas in Type $B$ spectra $\mathrm{n}_{1}=1000$ and $\mathrm{n}_{2}=5$. The use of different values of $\mathrm{n}_{1}$ enables the effect of damage or crack growth accelerations occurring due to load interaction effects to be highlighted. For both of these spectra, various maximum loads and changes in mean load were investigated, as shown in Table 1.

In the second group, the load amplitude was kept constant, but mean load and load ratio were different in the two stages of the spectrum, as shown in Fig. 2(b). Two variants of this spectrum, Type C and Type D, with different values of $n_{1}$, were investigated. In the third group of spectra, overloads were introduced, keeping the minimum load constant. This has the consequence that both mean load and the load ratio changed, in addition to amplitude. These spectra are shown in Fig. 2 (c). As with the previous spectra, two variants, Type $\mathrm{E}$ and Type $\mathrm{F}$ with different value of $\mathrm{n}_{1}$ were investigated. In the fourth group, the mean load was kept constant and overloads were introduced as shown in Fig. 2(d). This has the consequence that load ratio and amplitudes between stages in the spectrum changed. This type of spectra is called Type $\mathrm{G}$ and only one variant, with $\mathrm{n}_{1}=10$ and $\mathrm{n}_{2}=5$, was tested.

A detailed description of the different fatigue spectra used in the paper can be seen in Table 1. It can be seen that an extensive experimental programme was conducted involving all types of load interaction effect that may be present in a given complex loading history. For every type of spectrum other than A and $\mathrm{B}$ a single load and three specimens were tested. The common feature for all the spectra is testing 
with $\mathrm{L}_{\text {mean } 1}=3.575 \mathrm{kN}$. This provided a suitable base for exploring all the various load interaction, whilst avoiding excessively long or short lives or compressive loading and provided a means of comparing the different spectra.

\section{Experimental results}

\subsection{Fractography}

Optical and scanning electron microscopy examination of the fracture surfaces indicated that failure was predominantly by cohesive fracture of the adhesive layer. The fracture surfaces did not appear to be dependent to a significant extent on the type of loading. Typical fracture surfaces are shown in Fig. 3 (a) and Fig. 3 (b) is a schematic representation of the crack path seen in all the tested samples.

3.2 Quasi-static testing and constant amplitude fatigue

\subsubsection{Single lap joints (SLJs)}

The mean quasi static failure load (QSFL) for the five SLJ samples tested was $11.95 \mathrm{kN}$, with a standard deviation of $0.31 \mathrm{kN}$. In CAF testing, 23 samples were tested, at various fatigue loads. A plot of maximum fatigue load against the number of cycles to failure from the CAF testing is shown in Fig. 4 (a). A linear fit to the data has been made in which the standard deviation is $1.6 \mathrm{kN}$.

\subsubsection{Compound double cantilever beams (CDCBs)}

CDCB specimens were tested to determine the mode I critical strain energy release rate $\left(\mathrm{G}_{\mathrm{IC}}\right)$ in quasistatic testing and the relationship between crack propagation rate $(\mathrm{da} / \mathrm{dN})$ and strain energy release rate $\left(\mathrm{G}_{\mathrm{I}}\right)$ in fatigue testing. The $\mathrm{G}_{\mathrm{IC}}$ values were determined using eqn. 2:

$$
\mathrm{G}_{\mathrm{IC}}=\frac{\mathrm{P}_{\mathrm{C}}^{2}}{2 \mathrm{~b}} \frac{\mathrm{dC}}{\mathrm{da}}
$$


where, $\mathrm{P}_{\mathrm{C}}$ is the failure load corresponding to a crack length a, $\mathrm{dC} / \mathrm{da}$ is the change in compliance with respect to crack length and $b$ is the width of the specimen. The mean value of $G_{I C}$ was $2000 \mathrm{~J} / \mathrm{m}^{2}$ with a standard deviation of $450 \mathrm{~J} / \mathrm{m}^{2} . G_{\max }$ and $G_{\min }$ values for fatigue loading were calculated by substituting $\mathrm{P}_{\max }$ and $\mathrm{P}_{\min }$ respectively for $\mathrm{P}_{\mathrm{C}}$ in eqn. 2 . The detailed procedure for these calculations can be found in [32]. $\Delta \mathrm{G}$ is calculated as $\mathrm{G}_{\max }-\mathrm{G}_{\min }$. Fig. 4 (b) shows the crack growth rate, da/dN, plotted against $\Delta \mathrm{G}$ for a typical fatigue test. The plot illustrates three regions, as observed by previous workers. These are a threshold region, $\Delta \mathrm{G}_{\mathrm{th}}$, below which there is no crack growth, a Paris-type region, where $\log \mathrm{da} / \mathrm{dN}$ is approximately proportional to $\log \Delta \mathrm{G}$, and a rapid increase in slope, where $\mathrm{G}_{\max }$ approaches $\mathrm{G}_{\mathrm{IC}}$. The experimental data can be represented quite well by a straight line fit between the limits of $\Delta \mathrm{G}_{\mathrm{th}}$ and $\mathrm{G}_{\mathrm{IC}}$. In some cases a more complex sigmoidal fit [37] to such data is proposed, however, in this case the simpler straight-line fit was seen to provide equally good lifetime predictions. This curve represents the characteristic fatigue behaviour under fatigue loading for the FM $73 \mathrm{M}$ adhesive and can be used in lifetime prediction for different types of adhesive joint. The fitted curve in this case is given by,

$$
\frac{\mathrm{da}}{\mathrm{dN}}=3.5 \mathrm{E}-16(\Delta \mathrm{G})^{3.2}
$$

\subsection{Variable amplitude fatigue (VAF)}

A comparison of the results from the CAF and VAF tests for the first group of spectra, consisting of Types $A$ and $B$, in terms of $\mathrm{L}_{\max 1}$ can be seen in Fig. 5 . $\mathrm{L}_{\max 1}$ is chosen to compare the results in the first instance as the value of $\mathrm{L}_{\max 1}$ was common for all the spectra investigated and this enables the effect of various changes to the fatigue cycle to be investigated. The Type A spectra have $30 \%$ of cycles at a high load compared to $\mathrm{L}_{\max 1}$. It can be seen in Fig. 5 that this has the effect of significantly reducing the fatigue life, with the largest decrease coinciding with the greatest increase in mean load. Type B spectra have only $0.5 \%$ of cycles at the higher load; however, this still has a significant effect on the fatigue life when the mean load changes are 23 and $40 \%$, reducing the average fatigue life by 80 and $77 \%$, respectively. 
However, there is relatively little effect on fatigue life when the increase of the mean load change is $18.75 \%$, which also coincides with the smallest increase in amplitude (see Table 1).

A more effective method of comparing CAF and VAF is through the PM rule, given in eqn. 1. A damage sum, $\mathrm{D}_{\mathrm{PM}}$, equal to 1 , indicates no fatigue load interaction effects. The damage sums calculated for spectra Type A and Type B are given in Table 2. It can be seen that for the Type A spectra, the damage sum calculated for all loads is below a value of 1 , indicating a damage acceleration interaction effect. This is also the case for the Type $\mathrm{B}$ spectra, except for $\mathrm{L}_{\max 1}$ of $8 \mathrm{kN}$. On average, the $\mathrm{D}_{\mathrm{PM}}$ value calculated for Type B spectra is higher than that calculated for Type A spectrum, which is also an indication of load interaction effects as there are more load interaction events in the Type A spectrum. The PM rule could not be applied to the other spectra used in this paper because of the load ratio dependency of the CAF L-N curve, which was only obtained at $\mathrm{R}=0.1$. However, a comparison of the various VAF spectra in terms of $\mathrm{L}_{\max 1}$ is useful as this allows the effect of various types of change in the fatigue load to be compared.

The experimental results for all the VAF spectra with $\mathrm{L}_{\max }=6.5 \mathrm{kN}$ are shown in Table 3. As seen with spectra Type A and Type B, there is a decrease in fatigue lifetime for spectra C and D. Compared with CAF and, as expected, the decrease in life is greater for spectra Type B, which has a greater number of mean load changes. Comparing spectra $\mathrm{C}$ and $\mathrm{D}$ with $\mathrm{A}$ and $\mathrm{B}$, the former have a greater change in mean from one stage to another, which would be expected to be more detrimental, but the amplitude remains the same and the R ratio increases, which would be expected to be beneficial. It can be seen in Table 3 that the overall effect is that spectra $\mathrm{C}$ and $\mathrm{D}$ result in longer fatigue lives than $\mathrm{A}$ and $\mathrm{B}$.

The results from the third group of spectra are also shown in Table 3. Comparing spectra $\mathrm{E}$ and $\mathrm{F}$ with spectra A and B, it can be seen that the former has slightly lower mean load changes between stages, but slightly higher amplitude changes. The major difference is that only a single overload is applied in spectra $\mathrm{E}$ and $\mathrm{F}$ compared with 5 for $\mathrm{A}$ and $\mathrm{B}$. It can be seen in Table 3 that this results in spectra $\mathrm{E}$ and $\mathrm{F}$ having a less detrimental effect on the fatigue life than spectra $\mathrm{C}$ and $\mathrm{B}$. Comparing spectrum $\mathrm{G}$ with spectrum 
A, it can be seen from Table 1 that the main difference is that the amplitude increases, with constant mean in the former, whilst the reverse is the case in the latter. From Table 3 it can be seen be seen that the fatigue life is considerably shorter for spectrum $C$ that spectrum $G$, indicating that changes in mean are potentially more damaging than changes in amplitude. However, this may also be affected by the fact that the mean change in spectrum $\mathrm{C}$ is greater than the amplitude change in spectrum $\mathrm{G}$. This is because the requirement to avoid compression of the joints restricts the amplitude increases achievable whilst maintaining a constant mean.

In summary, it can be seen that relatively small numbers of cycles at higher fatigue loads can result in a large decrease in the number of cycles to failure. This is in agreement with previous work, which has indicated load interaction effects in the variable amplitude fatigue testing of bonded joints, with both mean load changes and overloads resulting in damage acceleration [10-14]. These effects need to be accommodated in any lifetime prediction procedure if the variable amplitude fatigue behaviour of adhesively bonded joints is to be accurately predicted. The next part of the paper is concentrated with the development and validation of such methods.

\subsection{Fatigue lifetime prediction}

\subsection{Theory}

In this paper two progressive damage modelling approaches are used to predict the fatigue lifetime of bonded joints subjected to VAF loading. The first approach is based on fracture mechanics (FM), in which the fatigue crack growth rate is related empirically to the strain energy release rate. The second method is based on damage mechanics, in which the rate of change of a state damage variable is related to the localised plastic strain. Both methods have been incorporated into a commercial finite element package through the use of external sub-routines. In the following sections, the details of the finite element analysis are given, followed by a description of the two progressive damage modelling methods. 


\subsubsection{Finite element details}

The commercial FEA package MSC Marc was used for all the simulations. A plane strain modeling approach using six noded triangular elements (Element 27 in MSC Marc element library) was used in the FM based approach as this enabled efficient re-meshing. Geometric non-linearity was accounted for in the analysis but material elasticity was assumed. In the case of the DM modelling a 3D model with eight noded hexahedral elements (Element 7 in MSC Marc) was used. Both material and geometric nonlinearity were accounted for in this analysis. Typical meshes taken from finite element models for each approach are shown in Figs. 6 (a) and (b).

In terms of boundary conditions, the joints were constrained in the vertical direction at the loaded end of the joint, as shown in Fig. 7(a) and (b). In the FM based models, rotational symmetry was used so that only half of the joint was modelled. This represented the modelling of symmetric crack growth from both ends of the overlap. In the DM based approach, both planar and symmetric boundary conditions were used enabling only a quarter of the joint to be modelled. The crack growth considered in this case was therefore of twofold symmetry.

The Young's moduli for adhesive and aluminium adherends were 2GPa and 70GPa respectively. The Mohr-Coulomb model [39] was used to model the adhesive in the DM based models, however, linear elasticity was assumed for the adherends as no plastic deformation was observed in the adherends during the experiments. The tensile yield stress of the adhesive was equal to $28.73 \mathrm{MPa}$ and was used with a yield surface modifier of 0.001057 (Jumbo, [40]) in the Mohr-Coulomb model.

\subsubsection{Fracture mechanics (FM) based lifetime prediction}

Two variants of numerical crack growth integration (NCGI) were used to predict fatigue lifetime under VAF. These were distinguished on the basis of different cycle counting procedures. In the first, NCGI-I, loading blocks in the VAF were considered separately, as shown schematically in Fig. 8(a). In NCGI-II, 
the cycle representing the transition from one block to the other was included in the cycle count, as illustrated in Fig. 8(b). The algorithm, written in Python (Python Software Foundation Inc., Hampton, USA) script language, used for the NCGI analysis is shown in Fig. 9 and can be described by the following steps.

Step 1: model the SLJ with an initial crack length, $\mathrm{a}_{0}$, and set the number of cycles, $\mathrm{N}$, to zero.

Step 2: perform quasi-static analysis for both the maximum fatigue load $\mathrm{L}_{\max }$ and the minimum fatigue $\operatorname{load} \mathrm{L}_{\min }$.

Step 3: determine $\mathrm{G}_{\max }$ and $\mathrm{G}_{\min }$, and, hence, $\Delta \mathrm{G}$ using the virtual crack closure technique [41]. If $\mathrm{G}_{\max }>\mathrm{G}_{\mathrm{IC}}, \mathrm{N}$ equals $\mathrm{N}_{\mathrm{f}}$, the number of cycles to failure. If $\Delta \mathrm{G}<\Delta \mathrm{G}_{\mathrm{th}}$, there is no crack growth.

Step 4: calculate the fatigue crack growth rate da/dN using:

$$
\frac{\mathrm{da}}{\mathrm{dN}}=\mathrm{C}_{\mathrm{F}}(\Delta \mathrm{G})^{\mathrm{m}_{\mathrm{F}}}
$$

Step 5: determine the new crack length using:

$$
a=a+d N \frac{d a}{d N}
$$

where $\mathrm{dN}$ is equal to either $\mathrm{n}_{1}$ or $\mathrm{n}_{2}$, depending upon which loading block is under consideration for the VAF loading spectrum.

Step 6: check if $a_{i}=a_{f}$, where $a_{f}$ is the crack length for fast crack growth. If yes, then $N=N_{f}$. If not, then change the loading level to the next loading level of the spectrum and repeat steps 1 to 4 until the crack length reaches the crack length for fast crack growth.

In cases where, the load ratio, $\mathrm{R}$, was different to that used in the fracture tests used to define the constant in eqn. 4, the constant $\mathrm{C}_{\mathrm{F}}$ was altered using eqn. 6 [42]: 


$$
\mathrm{C}_{\mathrm{Fmod}}=\frac{\mathrm{C}_{\mathrm{F}}}{(1-\mathrm{R})^{\mathrm{m}_{\mathrm{F}}(1-\gamma)}}
$$

where, $\mathrm{R}$ is the load ratio and the parameter $\gamma$ is set to 0.4 .

\subsubsection{Damage mechanics (DM) based lifetime prediction}

In this approach, the damage rate $\mathrm{dD} / \mathrm{dN}$ was assumed to be a power law function of the plastic strain range. This is given by:

$$
\frac{\mathrm{dD}}{\mathrm{dN}}=\mathrm{C}_{\mathrm{D}}\left(\Delta \varepsilon_{\mathrm{p}}\right)^{\mathrm{m}_{\mathrm{D}}}
$$

where, $\Delta \varepsilon_{\mathrm{p}}$ is the plastic strain range calculated from the maximum and minimum fatigue loads of a fatigue loading cycle. $C_{D}$ and $m_{D}$ are experimentally derived constants. The model was implemented using an external subroutine written in Python script language. This was interfaced with the MSC Marc software to simulate the damage and crack progression process. The algorithm used for the analysis is shown in Fig. 10. It can be described by the following steps:

step 1: model the SLJ with an initial crack length, $\mathrm{a}_{0}$, and set the number of cycles, $\mathrm{N}$, to zero.

Step 2: perform a non-linear static analyses for both maximum and minimum loads of the fatigue loading spectrum and determine the plastic strain range for each element in the adhesive layer.

Step 3: check if the analysis converges. If yes then step 4, otherwise $\mathrm{N}=\mathrm{N}_{\mathrm{f}}$ and stop the program.

Step 4: determine the damage rate $\mathrm{dD} / \mathrm{dN}$ for every element in the adhesive layer using eqn. 7.

Step 5: calculate a new value of damage for each element in the adhesive using: 


$$
\mathrm{D}=\mathrm{D}+\frac{\mathrm{dD}}{\mathrm{dN}} \mathrm{dN}
$$

where, $\mathrm{dN}$ is the selected increment to the number of cycles.

Step 6: check if $\mathrm{D}=1$, if yes then create a crack increment equal to the length of the element for which $\mathrm{D}$ $=1$, and go to step 2 .

Step 7: if $\mathrm{D} \neq 1$ then, for the new value of damage, calculate new material properties as:

$$
\begin{aligned}
& E=E_{0}(1-D) \\
& \sigma_{y p}=\sigma_{y p 0}(1-D) \\
& \beta=\beta_{0}(1-D)
\end{aligned}
$$

where $\mathrm{E}_{0}, \sigma_{\mathrm{yp} 0}$ and $\beta_{0}$ are Young's modulus, yield stress and plastic surface modifier constant for the Parabolic Mohr-Coulomb model respectively.

Step 7: change the load level to the next level of the fatigue loading spectrum and go to step 2.

The constants $C_{D}$ and $m_{D}$ were determined by repeating the procedure above for different values at two different fatigue loads under CAF and optimising. These constants were then kept constant to determine the life for other fatigue loads. In this way, $C_{D}$ and $m_{D}$ were used to completely characterise the mechanism of fatigue damage and failure of SLJs under CAF [36]. The same constants were then used for the VAF predictions.

\subsection{Results}

In Fig. 11, the crack growth for Type A and B spectra using the NCGI-I and NCGI-II cycle counting approaches are compared. The load combination $\mathrm{L}_{\max 1}$ and $\mathrm{L}_{\max 2}$ were 5 and $7 \mathrm{kN}$ respectively. In the case of Type A spectrum, the NCGI-II method has a higher crack growth rate than NCGI-I, whereas in the 
case of Type B, there is little difference between the two methods, which can be attributed to the reduced number of transitions. In addition, steps can be seen in the crack growth curves for the Type B spectrum that represent the change in crack growth associated with changes in the fatigue load. This is less noticeable in the Type A spectrum as the fatigue load changes are more frequent in this case (67 in 1000 cycles, compared with 1 in 1000 cycles for spectrum B).

In the DM based approach, damage prior to crack propagation is simulated as described in section 4.1.3. The evolution of damage in an element, E, in the vicinity of the embedded corner of the adhesive as indicated in Fig. 12 (a), is shown in Fig. 12(b). The load $\mathrm{L}_{\max 1}$ in this case is $6.5 \mathrm{kN}$. It can be seen that there is a non-linear increase in damage for both of the fatigue loading spectra. The damage growth rate for Type A is higher than for Type B because of the higher frequency of fatigue load changes. Crack growth at the centre of the joint is plotted for both spectra against number of cycles in Fig. 13. It can be seen that the crack initiation period, as well as the total life, for Type A is lower than for Type B. The life spent in crack initiation for Type A is $75 \%$, compared to $80 \%$ for Type B. It can be seen that crack growth is rapid towards the end of the fatigue life. A picture taken from the actual simulation is shown in Fig. 14. It can be seen that the elements are deleted in the central portion and moderately damaged elements can be seen ahead of the crack front in the adhesive layer.

The fatigue lifetime prediction results for spectra A and B using both FM and DM methods can be seen in Fig. 15 (a). In the case of spectrum A, it can be seen that both the FM approaches predict the fatigue lifetime well at low cycles but under predict the fatigue life at higher cycles. This may be because at low cycles the initiation period is smaller, as reported in previous work [35]. NCGI-I provides a slightly better fit to the experimental data than NCGI-II. The under-prediction of the fatigue life may be attributed to the absence of a crack initiation phase in the FM based simulations. The FM method, also does not account for any accelerative cycle interaction effects, as previously reported in $[10,12]$. Hence, it may be expected, if these were significant, that it would over-predict the fatigue lifetime. However, in this case this effect appears to be more than compensated for by not accounting for the crack initiation phase. 
In the case of the Type B spectrum both, of the FM based approaches significantly under-predict the fatigue lifetime, as shown in Fig. 15 (b), however the difference between NCGI-I and NCGI-II is smaller because of the lower frequency of fatigue load changes than in Type A. It would be expected in this case that any load interaction effect would be less significant than seen with spectrum A and this may explain why there is a more significant under-prediction of the fatigue life for spectrum B. With spectrum A the under-prediction of the fatigue life from ignoring the initiation phase is partly offset by the effect of ignoring the previously observed accelerative damage interaction effects. The latter is less significant in the case of spectrum B and hence the under-prediction of fatigue life is more pronounced. It is theoretically possible that in the FM approach, errors from neglecting the initiation phase could be completely offset by error from ignoring interaction effects to result in the false impression of a good predictive method.

The DM approach, in contrast to the FM approach, automatically account for both a fatigue initiation phase and load interaction effects. In this method, damage continuously develops in a damage (or process) zone ahead of the crack tip. For a decrease in the severity of fatigue load, crack growth will be initially through a more highly damaged region, resulting in an accelerative fatigue load interaction effect, as proposed in previous work $[10,12]$. Fig. 15 shows that the DM approach provides a reasonably good prediction of fatigue life for both spectral, though there is a tendency to over-predict the fatigue life, especially in the case of spectrum B. The reason for the over-prediction of fatigue life is not clear, and further investigation of both the nature and implementation of the proposed damage law are worthy of further investigation.

Similar fatigue lifetime predictions were also made for the other spectra and the results are summarised in Table 4. It can be seen that both FM methods always significantly under-predict the fatigue life, with NCGI-I providing slightly better predictions. The DM method, in contrast always over-predicts the fatigue life. However, a comparison of prediction error with the standard deviation in the experiments 
from table 4 shows that for the DM method, in 6 out of 7 cases the prediction is within the experimental scatter, whilst in the case of FM, this is only the case for 1 of the predictions.

\section{Conclusions}

It can be concluded from the experimental VAF testing that even a small number of fatigue cycles at a higher mean load or load amplitude can result in a significant decrease in the fatigue life. Application of the Palmgren-Miner law to the VAF fatigue data indicated significant load interaction effects in most cases, which had the effect of accelerating damage and hence reducing the fatigue life. The first method of predicting fatigue failure used numerical crack growth integration with a fracture mechanics based crack growth law. This method does not take load interaction effects into account and, hence, may be expected to over-predict the fatigue life if these accelerate damage. However, it was actually seen that the fracture mechanics method consistently under-predicted the fatigue life. This is attributed to the fact that the method also ignores any crack initiation phase in the fatigue life and that this effect is more dominant than the load interaction effects. A progressive damage method based on relating localised damage to plastic strain in an empirical continuum damage law was also investigated. This method models both the initiation and propagation phases of the fatigue life and also accounts for load history effects. In contrast to the fracture mechanics method, the damage mechanics method tends to over-predict the fatigue life. However, in most cases the damage mechanics method predicts a fatigue life within the experimental scatter, which is not the case for the fracture mechanics method. Further development of the damage mechanics method is required, both in the form of the damage law used and how it is implemented within the FEA software, however, it is clear from the results to date that this method has great potential for predicting fatigue failure in bonded joints subjected to VAF.

\section{References}

1. Johnson S, Mall S. A fracture mechanics approach for designing adhesively bonded joints. ASTM STP. 1985; 876: 189-199.

2. Kinloch AJ, Osiyemi SO. Predicting the fatigue life of adhesively bonded joints. J Adhes. 1993; 43: 79.

3. Xu XX, Crocombe AD, Smith PA. Mixed-mode fatigue and fracture behaviour of joints bonded with either filled or filled and toughened adhesive. Int J Fat. 1997; 17: 279-286. 
4. Dessureault M, Spelt JK. Observations of fatigue crack initiation and propagation in an epoxy adhesive. Int J Adhes Adhes. 1997; 17:183-195.

5. Lefebvre DR, Dillard DA. A stress singularity approach for the prediction of fatigue crack initiation in adhesive bonds. Part I: theory. J Adhes. 1999; 70: 119-138.

6. Cheuk PT, Tong T, Wang CH, Baker A, Chalkley P. Fatigue crack growth in adhesively bonded composite-metal double-lap joints. Comp Struct. 2002; 57: 109-115.

7. Ashcroft IA, Crocombe AD. Fatigue in adhesively bonded joints. In: da Silva LFM, Oechsner Andreas, Modelling failure in adhesively bonded joints. Springer, 2008; 184-187.

8. Ashcroft IA. Fatigue. In: Adams RD, Adhesive bonding science, technology and applications. Woodhead publishing, 2005; 209-239.

9. Quaresimin M. Modelling of fatigue behaviour of bonded joints in composite materials. Woodhead publishing, 2005; 469-494.

10. Erpolat S, Ashcroft IA, Crocombe AD, Abdel-Wahab MM. Fatigue crack growth acceleration due to intermittent overstressing in adhesively bonded CFRP joints. Comp A. 2004; 35: 11751183.

11. Erpolat S, Ashcroft IA, Crocombe AD, Abdel-Wahab MM. A study of adhesively bonded joints subjected to constant and variable amplitude fatigue. Int J Fat. 2004; 26: 1189-1196.

12. Ashcroft IA. A simple model to predict crack growth in bonded joints and laminates under variable amplitude fatigue. J Str Anal. 2004; 39: 707-716.

13. Gomatam R, Sancaktar E. A novel cumulative fatigue damage model for electronicallyconductive adhesive joints under variable loading. J Adhes. Sci. Tech. 2006; 20: 69-86.

14. Shenoy V, Ashcroft IA, Critchlow GW, Crocombe AD, Abdel-Wahab MM. An evaluation of strength wearout models for the lifetime prediction of adhesive joints subjected to variable amplitude fatigue. Int J Adhes Adhes. 2009; in press.

15. Palmgren A. Die Lebensdauer von Kugellargen. Zeitschrift des Vereins Deutscher Ingenieure. 1924; 68: 339-41. 
16. Agerskov H. Fatigue in steel structures under random loading. J Constr Steel Res. 2000; 53: 283-305.

17. Nisitani H, Nakamura K. Trans Japan Soc. Mech Eng. 1982; 48: 990 (in Japanese).

18. Farrow IR. Damage accumulation and degradation of composite laminates under aircraft service loading: assessment and prediction PhD thesis. vols. 1 and 2, Cranfield Institute of Technology, 1989.

19. Chang JB, Szamossi M, Liu KW. Eds. Chung JB, Hudson CM, editors. ASTM STP 748. USA ASTM 1979: 115-32.

20. Schaff JR, Davidson BD. Lifetime prediction methodology for composite structures part-I constant amplitude and two-stress level fatigue. J Comp Mat. 1997; 31(2): 128-57.

21. Schaff JR, Davidson BD. Lifetime prediction methodology for composite structures part-II spectrum fatigue. J Comp Mat. 1997; 31(2): 158-81.

22. Miner MA. Cumulative damage in fatigue. J Appl Mech. 1945; 12: 159-64.

23. Marco SM, Starkley WL. A concept of fatigue damage. Trans ASME. 1954; 76: 627-632.

24. Hahn HT, Kim RY. Proof testing of composite materials. J Comp Mat. 1975; 9: 297-311.

25. Hahn HT, Kim RY. Fatigue behaviour of composite materials. J Comp Mat. 1976; 10: 156-180.

26. Hwang W, Han KS. Fatigue of Composites- Fatigue modulus concept and life prediction. J Comp Mat. 1986; 20: 154-165.

27. Paris P, Erdogan F. A critical analysis of crack propagation law. J Basic Engg, trans. ASME 1963: 528-534.

28. Elber W. Fatigue crack closure under cyclic tension. Engg Fract Mech. 1970; 2(1): 37-44.

29. Newman JrJC (1997). Proc.Engineering against fatigue, University of Sheffield, NASA Langley Research Centre Hampton Virginia USA. 1997.

30. Abdel Wahab MM, Ashcroft IA, Crocombe AD, Shaw SJ. Prediction of fatigue threshold in adhesively bonded joints using damage mechanics and fracture mechanics. J Adhe Sci Tech. 2001; 7: 763-781. 
31. Critchlow G, Ashcroft I, Cartwright T, Bahrani D. Anodising aluminium alloy, UK patent no. GB 2421959A, US patent no. 20080213618.

32. Blackman BRK, Kinloch AJ. Fracture tests for structural adhesive joints. Amsterdam: Elsevier Science, 2001.

33. Adams RD, Comyn J, Wake WC. Structural adhesives in engineering. London: Chapman and Hall, 1997.

34. Shenoy V, Ashcroft IA, Critchlow GW, Crocombe AD, Abdel Wahab MM. Strength wearout of adhesively bonded joints under constant amplitude fatigue. Int J Fat. 2009; 31(5): 820-830.

35. Shenoy V, Ashcroft IA, Critchlow GW, Crocombe AD, Abdel Wahab MM. An investigation into crack initiation and propagation behaviour of bonded single-lap joints using backface strain. Int $\mathrm{J}$ Adhes Adhes. 2009; 29: 361-371.

36. Shenoy V, Ashcroft IA, Critchlow GW, Crocombe AD, Abdel Wahab MM. Prediction of fatigue damage and crack growth in adhesively bonded joints using progressive damage methods. Int $\mathbf{J}$ Solid Struct. Submitted.

37. Ewalds HL. Fracture mechanics. London: Edward Arnold, 1984.

38. Erpolat S. Lifetime prediction of adhesively bonded joints under variable amplitude fatigue. $\mathrm{PhD}$ Thesis, Loughborough University. 2004: 163-170.

39. Coulomb CA. Essai sur une application des regles des maxims et minimus a quelquels problemesde statique relatifs, a la architecture. Mem Acad Roy Sav. 1776; 7: 343-387.

40. Jumbo F. Modelling residual stresses and environmental degradation in adhesively bonded joints. $\mathrm{PhD}$ Thesis, Loughborough University. 2007: 208-210.

41. Krueger R. The virtual crack closure technique: history, approach and applications. ICASE report no. 2002-10, NASA/CR-2002-211628, 2002.

42. Dowling NE. Mechanical behaviour of materials. New Jersey: Prentice Hall, 1999. 
Table 1 Description of VAF spectra.

\begin{tabular}{|c|c|c|c|c|c|c|c|c|c|c|c|c|c|}
\hline \multirow{2}{*}{$\begin{array}{l}\text { Spectrum } \\
\text { type }\end{array}$} & \multicolumn{2}{|c|}{ Load } & \multicolumn{2}{|c|}{ Cycles } & \multirow{2}{*}{$\begin{array}{l}\mathrm{L}_{\text {mean1 }} \\
{[\mathrm{kN}]}\end{array}$} & \multirow{2}{*}{$\begin{array}{l}\mathrm{L}_{\text {mean2 }} \\
{[\mathrm{kN}]}\end{array}$} & \multirow{2}{*}{$\begin{array}{c}\% \\
\text { change }\end{array}$} & \multirow{2}{*}{$\mathrm{R}_{1}$} & \multirow{2}{*}{$\mathrm{R}_{2}$} & \multirow{2}{*}{$\begin{array}{c}\% \\
\text { change }\end{array}$} & \multirow{2}{*}{$\mathrm{L}_{\mathrm{a} 1}$} & \multirow{2}{*}{$\mathrm{L}_{\mathrm{a} 2}$} & \multirow{2}{*}{$\begin{array}{c}\% \\
\text { change }\end{array}$} \\
\hline & $\begin{array}{l}\mathrm{L}_{\max 1} \\
{[\mathrm{kN}]}\end{array}$ & $\begin{array}{l}\mathrm{L}_{\max 2} \\
{[\mathrm{kN}]}\end{array}$ & $\mathrm{n}_{1}$ & $\mathrm{n}_{2}$ & & & & & & & & & \\
\hline A & 5 & 7 & 10 & 5 & 2.75 & 3.85 & 40 & 0.1 & 0.1 & - & 2 & 3.15 & 57.5 \\
\hline A & 6.5 & 8 & 10 & 5 & 3.575 & 4.4 & 23 & 0.1 & 0.1 & - & 2.93 & 3.6 & 23 \\
\hline A & 8 & 9.5 & 10 & 5 & 4.4 & 5.225 & 18.75 & 0.1 & 0.1 & - & 3.6 & 4.3 & 19.4 \\
\hline B & 5 & 7 & 1000 & 5 & 2.75 & 3.85 & 40 & 0.1 & 0.1 & - & 2 & 3.15 & 57.5 \\
\hline B & 6.5 & 8 & 1000 & 5 & 3.575 & 4.4 & 23 & 0.1 & 0.1 & - & 2.93 & 3.6 & 23 \\
\hline B & 8 & 9.5 & 1000 & 5 & 4.4 & 5.225 & 18.75 & 0.1 & 0.1 & - & 3.6 & 4.3 & 19.4 \\
\hline $\mathrm{C}$ & 6.5 & 8 & 10 & 5 & 3.575 & 5.075 & 42 & 0.1 & 0.27 & +169 & 2.93 & 2.93 & - \\
\hline D & 6.5 & 8 & 1000 & 5 & 3.575 & 5.075 & 42 & 0.1 & 0.27 & +169 & 2.93 & 2.93 & - \\
\hline $\mathrm{E}$ & 6.5 & 8 & 10 & 1 & 3.575 & 4.325 & 21 & 0.1 & 0.08 & -19 & 2.93 & 3.68 & 26 \\
\hline F & 6.5 & 8 & 1000 & 1 & 3.575 & 4.325 & 21 & 0.1 & 0.08 & -19 & 2.93 & 3.68 & 26 \\
\hline $\mathrm{G}$ & 6.5 & 7 & 10 & 5 & 3.575 & 3.575 & - & 0.1 & 0.02 & -80 & 2.93 & 3.43 & 17 \\
\hline
\end{tabular}


Table 2 PM damage sum calculated for Type A and B spectra.

\begin{tabular}{cccc}
\hline & & \multicolumn{2}{c}{ PM damage sum $\left(\mathrm{D}_{\mathrm{PM}}\right)$} \\
\cline { 3 - 4 } $\mathrm{L}_{\max 1}[\mathrm{kN}]$ & $\mathrm{L}_{\max 2}[\mathrm{kN}]$ & Type A & Type B \\
\hline 5 & & 0.29 & 0.51 \\
6.5 & 7 & 0.81 & 0.49 \\
8 & 9.5 & 0.57 & 1.42 \\
\hline
\end{tabular}


Table 3 Comparison of VAF with CAF for Type A to $\mathrm{H}$ spectra based on $\mathrm{L}_{\max 1}$.

\begin{tabular}{|c|c|c|c|c|c|}
\hline \multirow{3}{*}{ Spectrum type } & \multirow{3}{*}{$\begin{array}{l}\mathrm{L}_{\max 1} \\
{[\mathrm{kN}]}\end{array}$} & \multirow{3}{*}{$\begin{array}{l}\mathrm{L}_{\max 2} \\
{[\mathrm{kN}]}\end{array}$} & \multicolumn{2}{|c|}{$\begin{array}{l}\text { Cycles to failure, } \\
\qquad \mathrm{N}_{\mathrm{f}}\end{array}$} & \multirow{3}{*}{$\mathrm{VAF} / \mathrm{CAF}^{*}$} \\
\hline & & & \multicolumn{2}{|c|}{ VAF } & \\
\hline & & & Mean & $\pm \mathrm{SD}(\%)$ & \\
\hline A & 6.5 & 8 & 6379 & 84 & 0.8 \\
\hline B & 6.5 & 8 & 16730 & 15 & 0.19 \\
\hline $\mathrm{C}$ & 6.5 & 8 & 8969 & 20 & 0.10 \\
\hline $\mathrm{D}$ & 6.5 & 8 & 29455 & 63 & 0.34 \\
\hline $\mathrm{E}$ & 6.5 & 8 & 8987 & 34 & 0.10 \\
\hline $\mathrm{F}$ & 6.5 & 8 & 38486 & 45 & 0.44 \\
\hline G & 6.5 & 7 & 16753 & 50 & 0.19 \\
\hline
\end{tabular}

$* \mathrm{~N}_{\mathrm{f}}$ for CAF with $\mathrm{L}_{\max }=6.5 \mathrm{kN}$ is $8.66 \times 10^{4}$ with standard deviation (SD) of $\pm 87 \%$ 
Table 4 Comparison between experimental and predicted cycles to failure for all spectra tested with $\mathrm{L}_{\max 1}=6.5 \mathrm{kN}$.

\begin{tabular}{ccccccccc}
\hline \multirow{2}{*}{$\begin{array}{c}\text { Spectrum } \\
\text { type }\end{array}$} & $\begin{array}{c}\text { Experimental } \\
(\text { Cycles to failure })\end{array}$ & \multicolumn{3}{c}{$\begin{array}{c}\text { Prediction } \\
\text { (Cycles to failure) }\end{array}$} \\
\cline { 2 - 9 } & Mean & $\begin{array}{c} \pm \text { SD } \\
(\%)\end{array}$ & NCGI-I & NCGI-II & DM & NCGI-I & NCGI-II & DM \\
\hline A & 6379 & 84 & 1920 & 1696 & 11000 & -69.90 & -73.41 & 72.44 \\
B & 16268 & 16 & 8015 & 7501 & 24500 & -50.73 & -53.89 & 50.60 \\
C & 8969 & 20 & 2115 & 1886 & 7462 & -76.40 & -82.60 & 16.80 \\
D & 29455 & 63 & 6030 & 5026 & 33164 & -79.52 & -92.96 & 12.58 \\
E & 8987 & 40 & 2629 & 1965 & 17443 & -70.41 & -79.28 & 94.07 \\
F & 38486 & 45 & 6006 & 6005 & 34607 & -84.39 & -76.90 & 10.07 \\
G & 16753 & 50 & 3536 & 3490 & 21995 & -78.89 & -79.16 & 31.22 \\
\hline
\end{tabular}



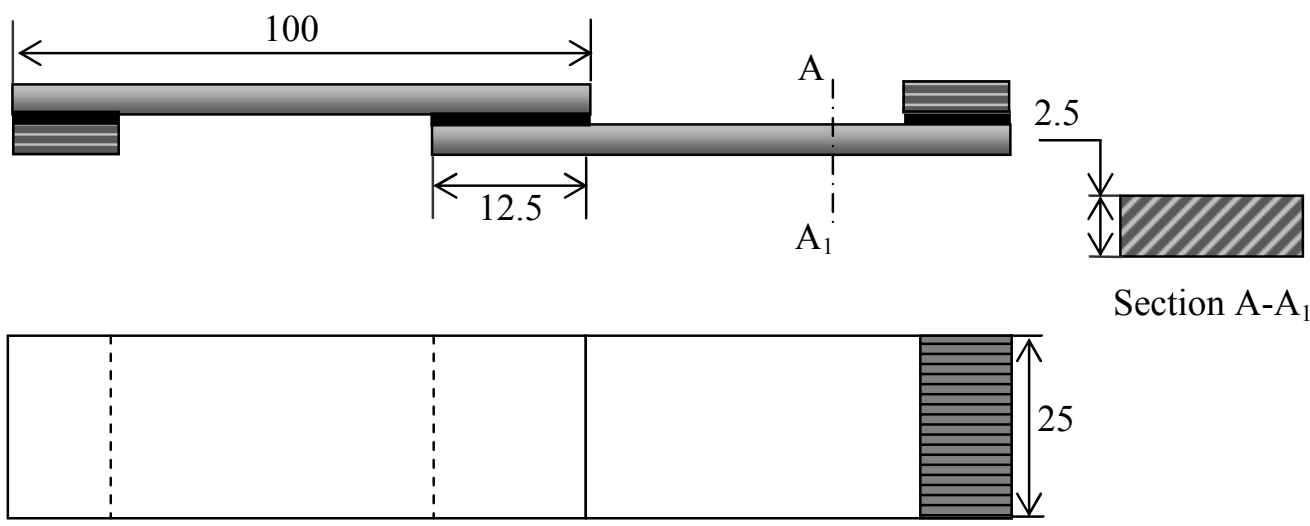

Section A-A

(a)

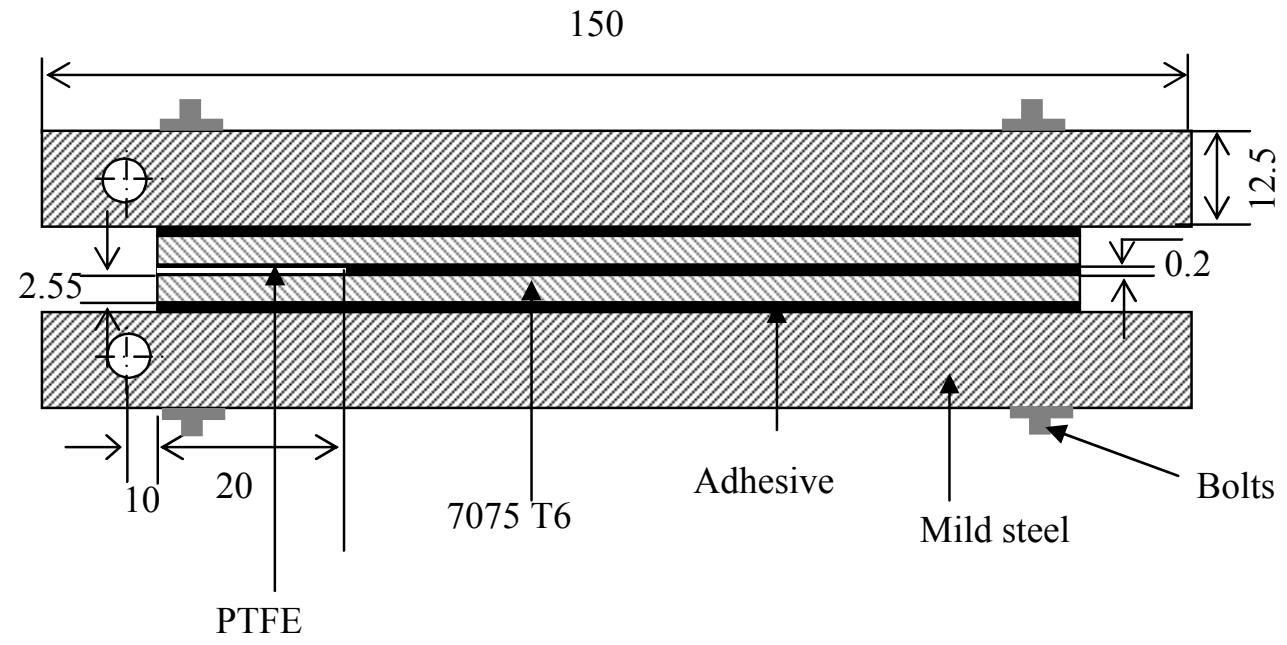

(b)

Fig. 1 (a) Single lap joint (SLJ), (b) compound double cantilever beam (CDCB). Dimensions in mm. 


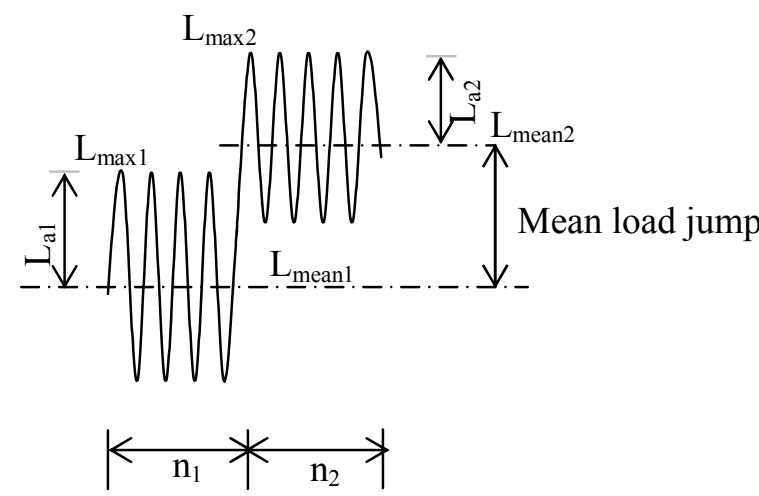

Type A: $\mathrm{n}_{1}=10 ; \mathrm{n}_{2}=5$

Type B: $\mathrm{n}_{1}=1000 ; \mathrm{n}_{2}=5$

$\mathrm{L}_{\mathrm{a} 1} \neq \mathrm{L}_{\mathrm{a} 2} ; \mathrm{R}_{1}=0.1 ; \mathrm{R}_{2}=0.1$

(a)

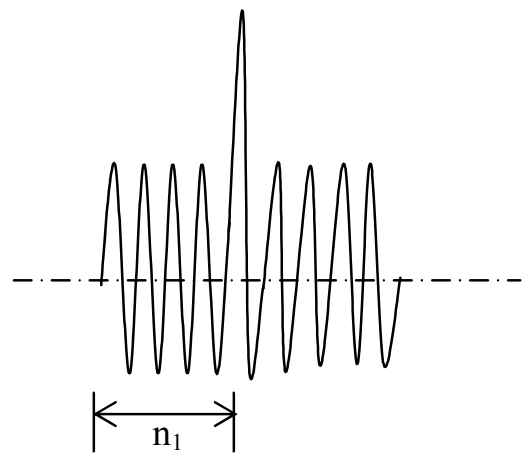

Type E: $\mathrm{n}_{1}=10 ; \mathrm{n}_{2}=1$

Type F: $\mathrm{n}_{1}=1000 ; \mathrm{n}_{2}=1$

$\mathrm{L}_{\mathrm{a} 1} \neq \mathrm{L}_{\mathrm{a} 2} ; \mathrm{R}_{1}=0.1 ; \mathrm{R}_{2}=0.08$

(c)

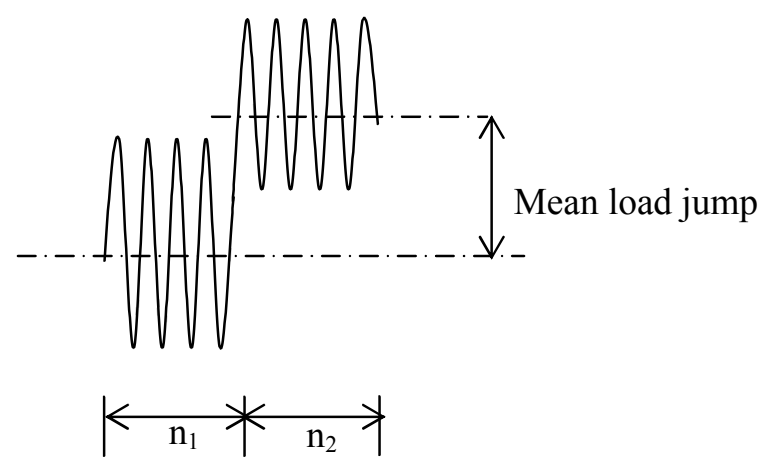

Type C: $\mathrm{n}_{1}=10 ; \mathrm{n}_{2}=5$

Type D: $\mathrm{n}_{1}=1000 ; \mathrm{n}_{2}=5$

$\mathrm{L}_{\mathrm{a} 1}=\mathrm{L}_{\mathrm{a} 2} ; \mathrm{R}_{1}=0.1 ; \mathrm{R}_{2}=0.27$

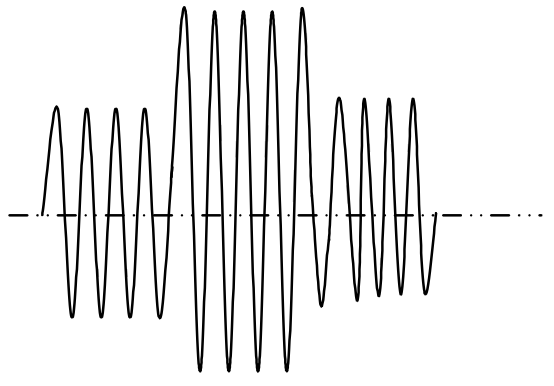

Type G: $\mathrm{n}_{1}=10 ; \mathrm{n}_{2}=5$

$\mathrm{L}_{\mathrm{a} 1} \neq \mathrm{L}_{\mathrm{a} 2} ; \mathrm{L}_{\text {mean } 1}=\mathrm{L}_{\text {mean } 2}$

$\mathrm{R}_{1}=0.1 ; \mathrm{R}_{2}=0.02$

Fig. 2.Showing (a) Type A and B spectra, (b) Type C and D spectra, (c) Type E and F spectra and (d) Type G spectrum. 


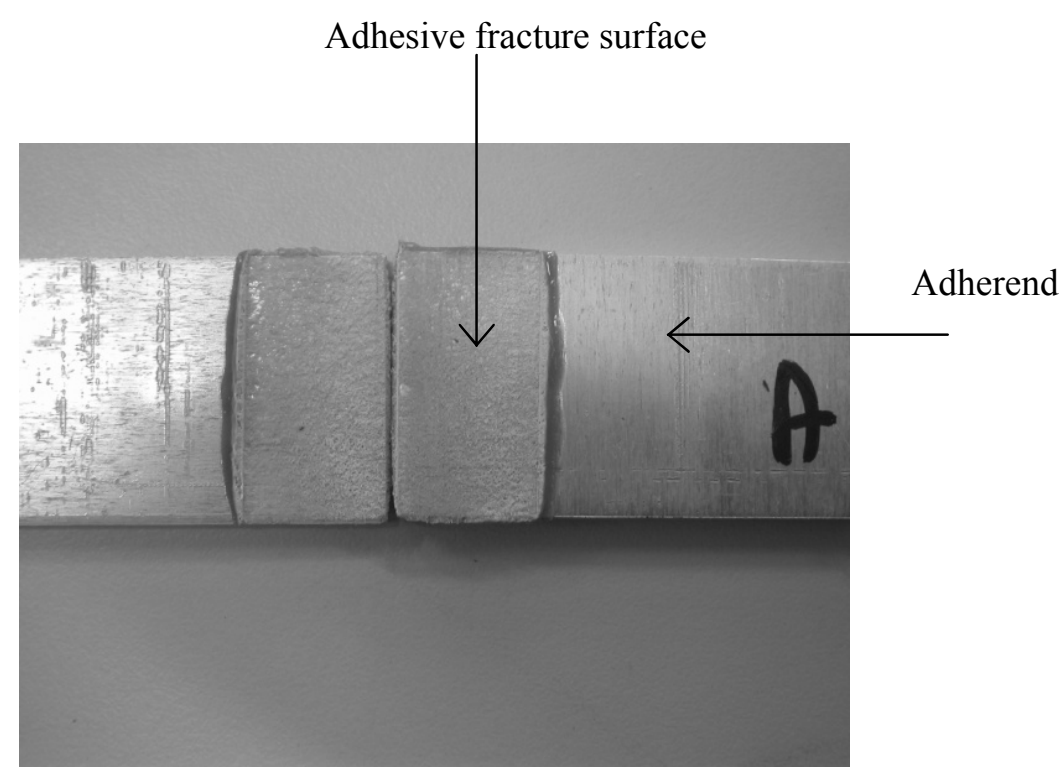

(a)

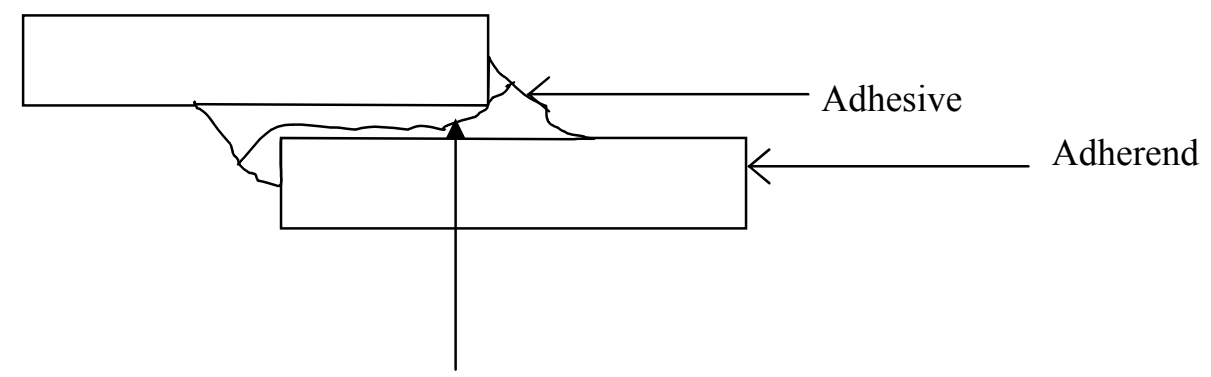

Crack path

(b)

Fig. 3. (a) Typical fracture surface and (b) typical crack path. 


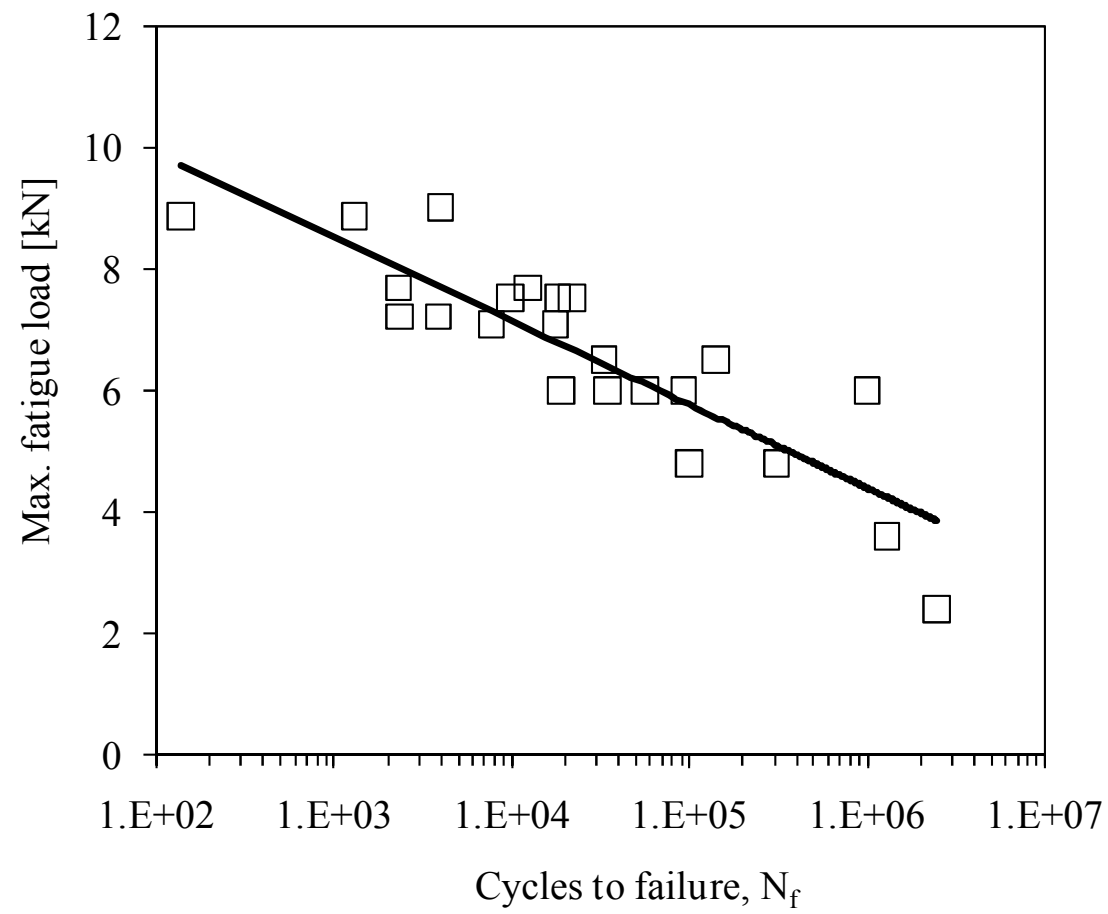

(a)

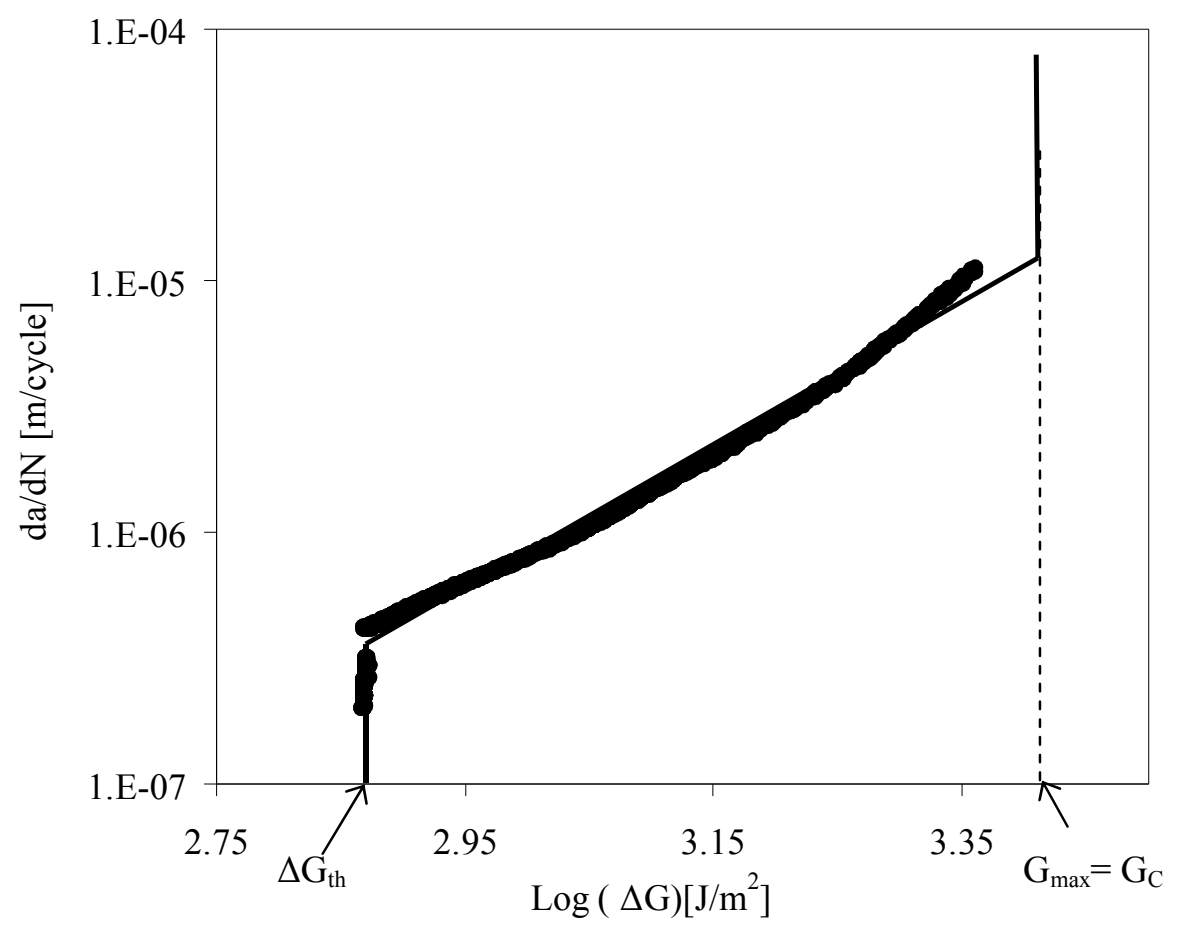

(b)

Fig. 4. (a) L-N curve for SLJs with aluminium 7075 T6 adherend and FM 73 adhesive, (b) fatigue crack growth rate plotted against $\log (\Delta \mathrm{G})$. 


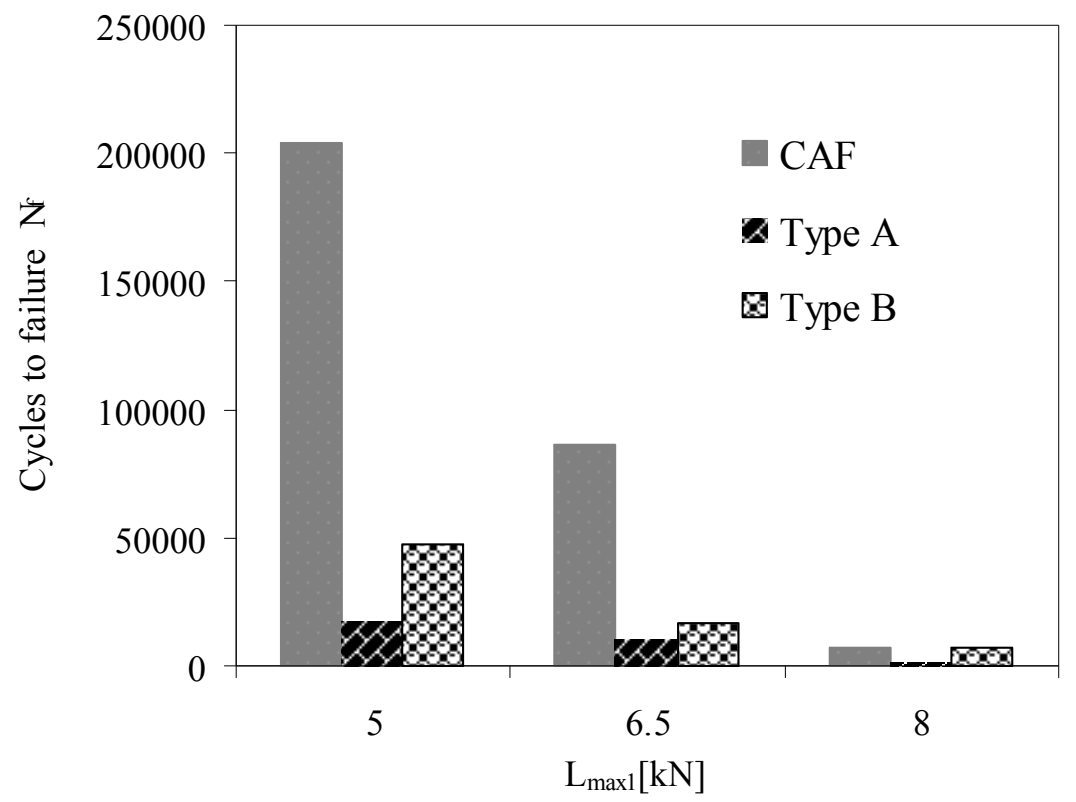

Fig. 5. Comparison of cycles to failure for CAF and VAF for Type A and Type B spectra as a function of $\mathrm{L}_{\max 1}$. 


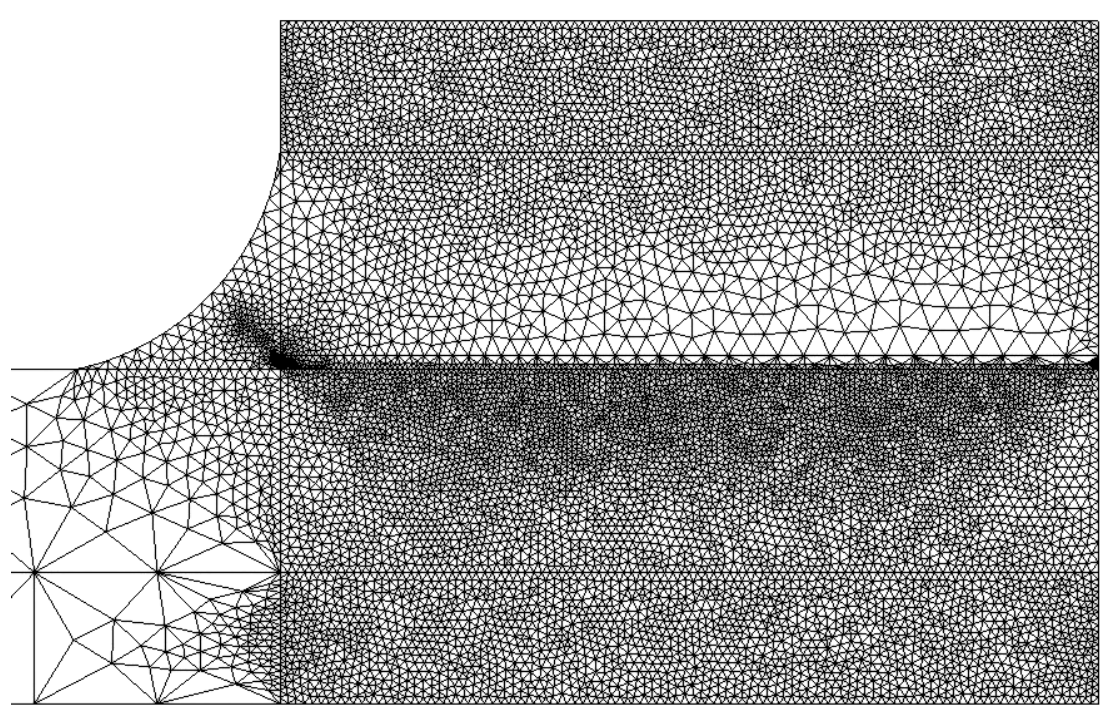

(a)

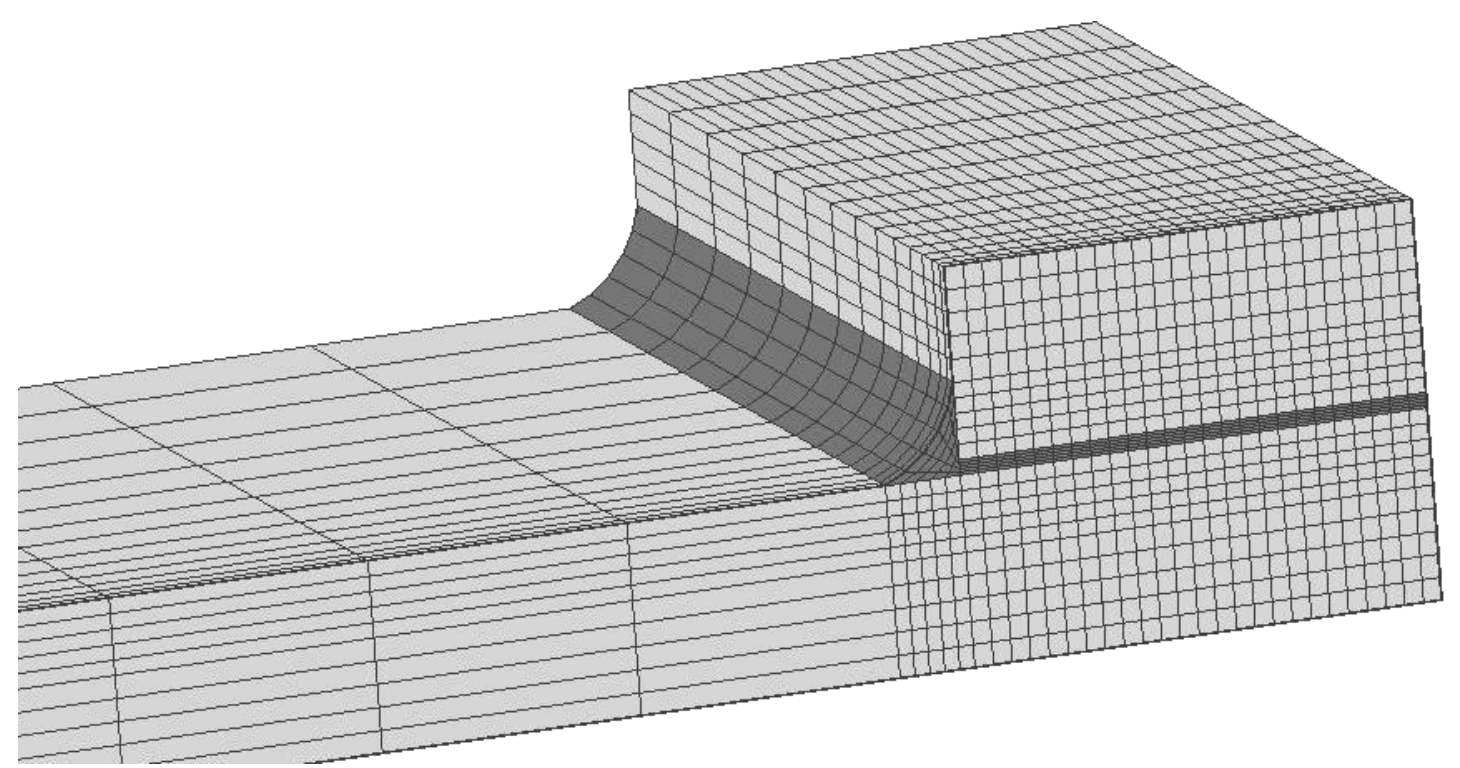

(b)

Fig. 6. Typical finite element mesh for (a) FM based simulation and (b) DM based simulation. 

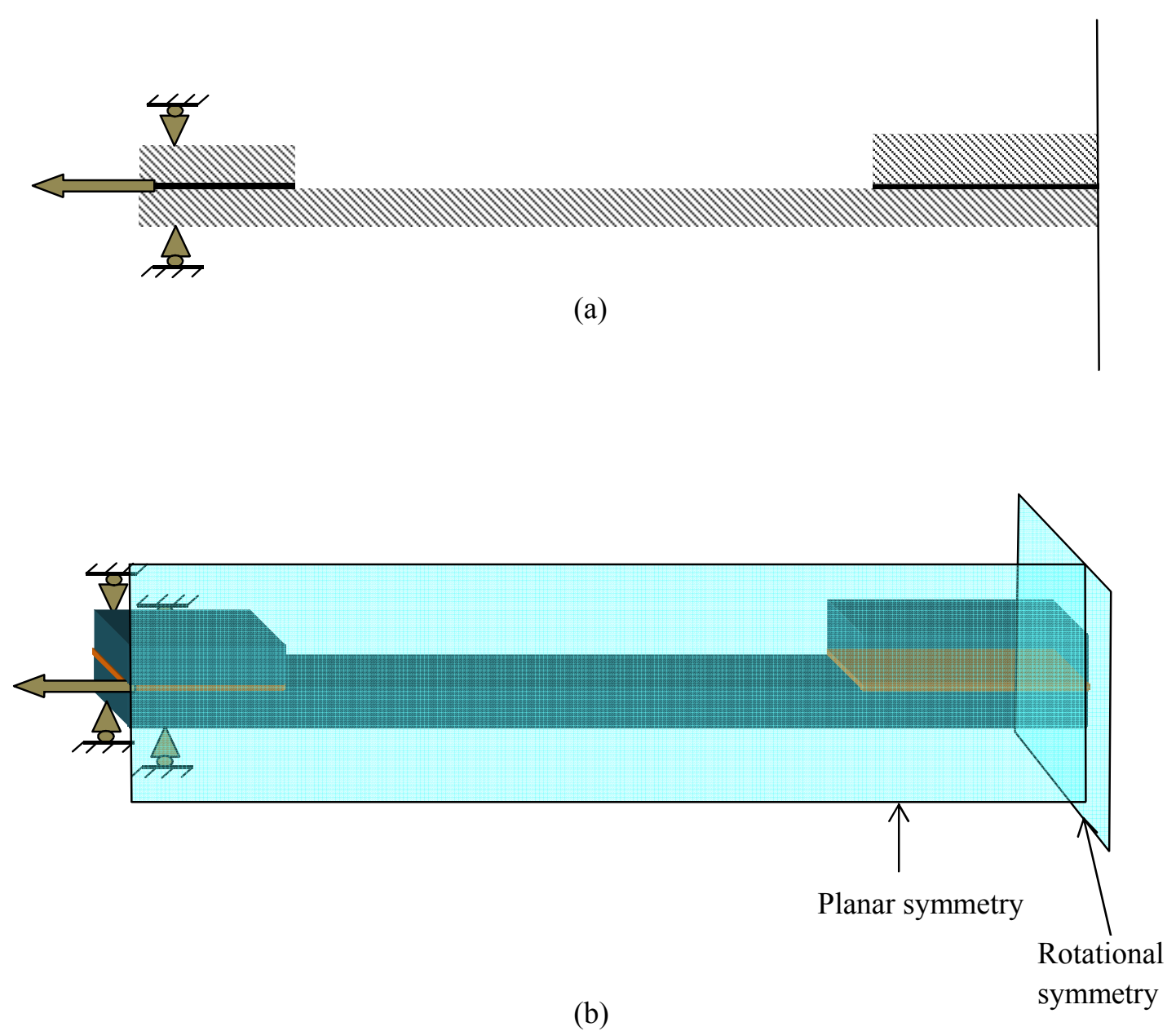

Fig. 7. Boundary conditions for (a) FM based simulation and (b) DM based simulations. 

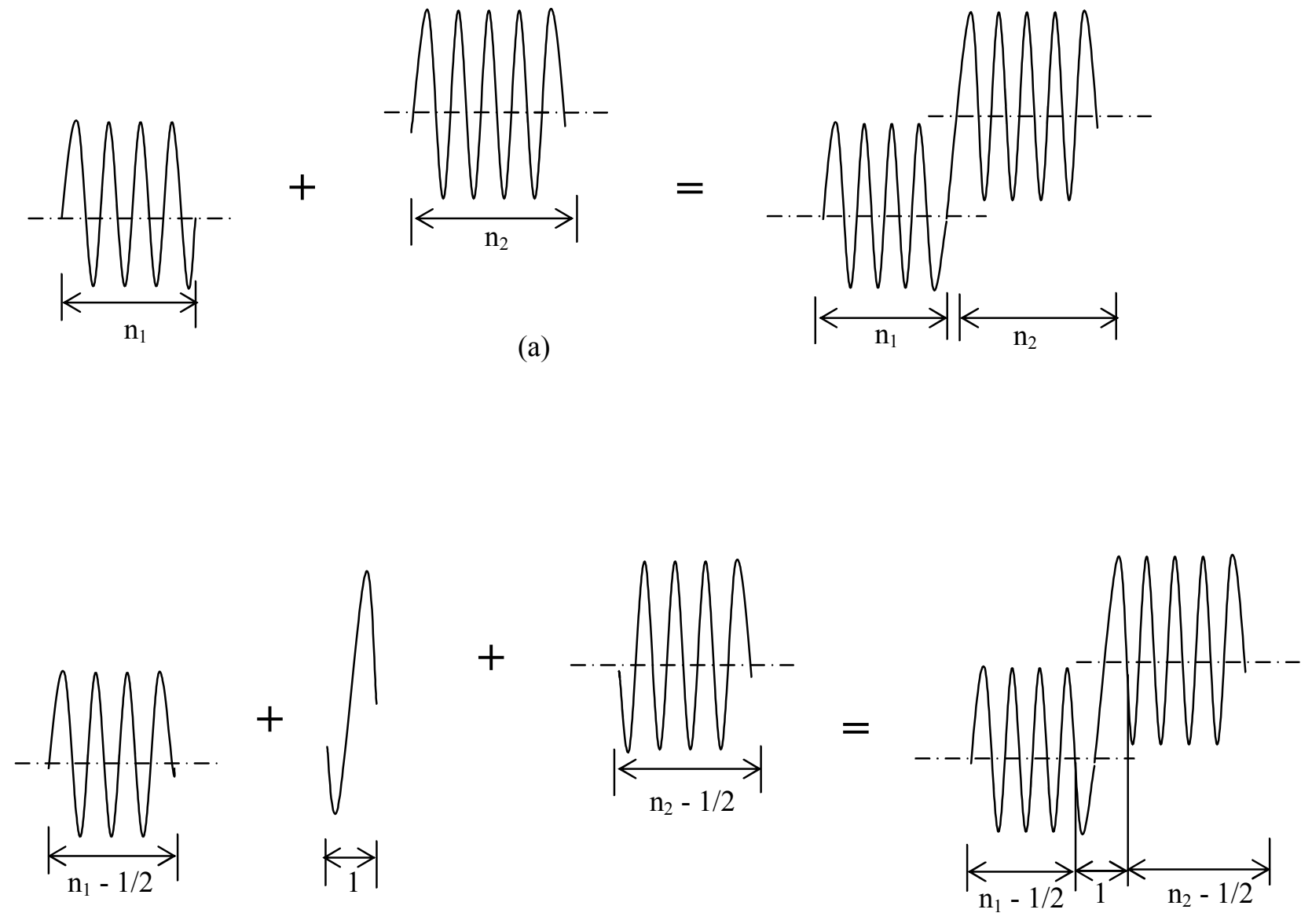

(b)

Fig. 8. Cycle counting method for (a) NCGI-I and (b) NCGI-II. 


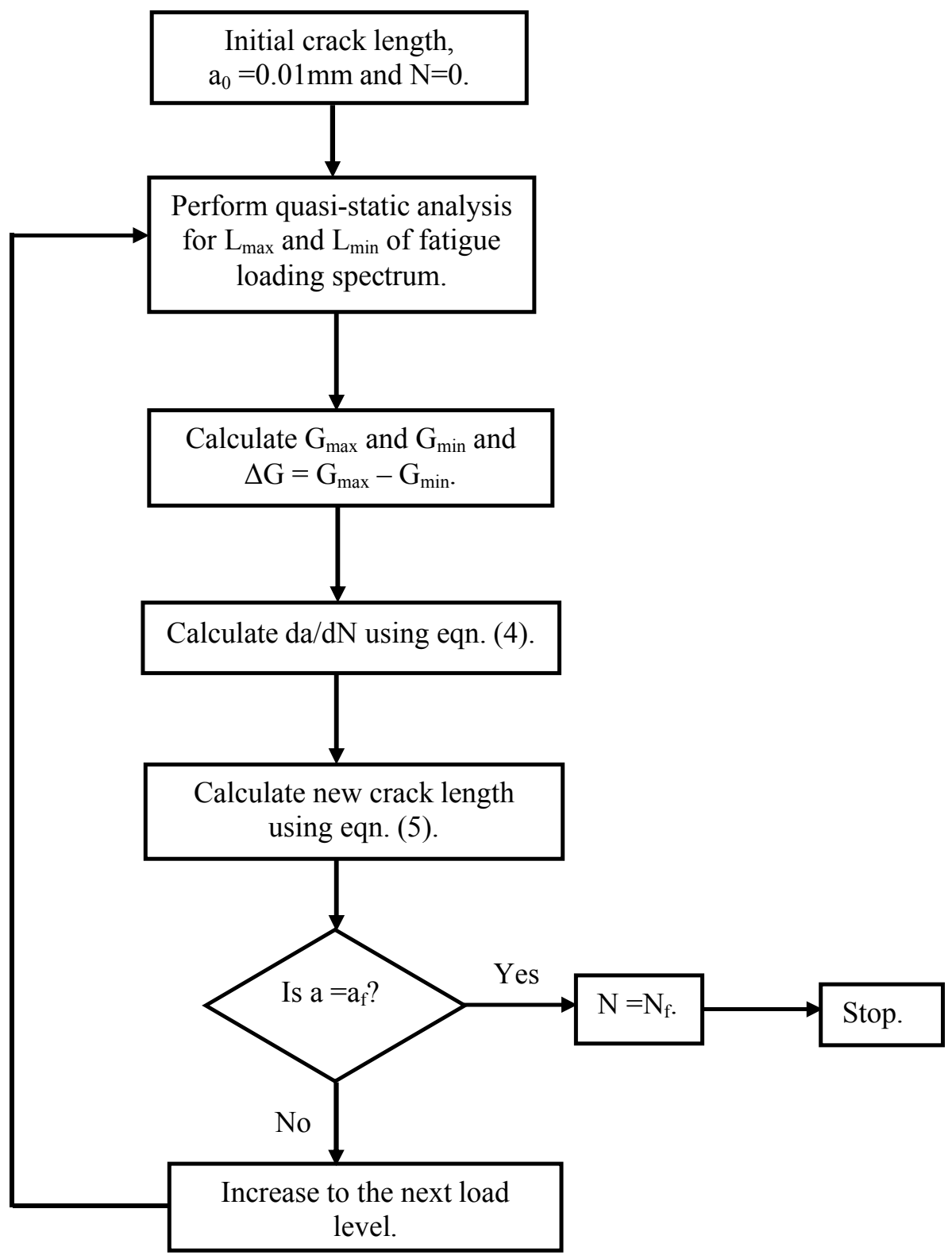

Fig. 9. Algorithm used for NCGI approach under FM based approach for lifetime prediction. 


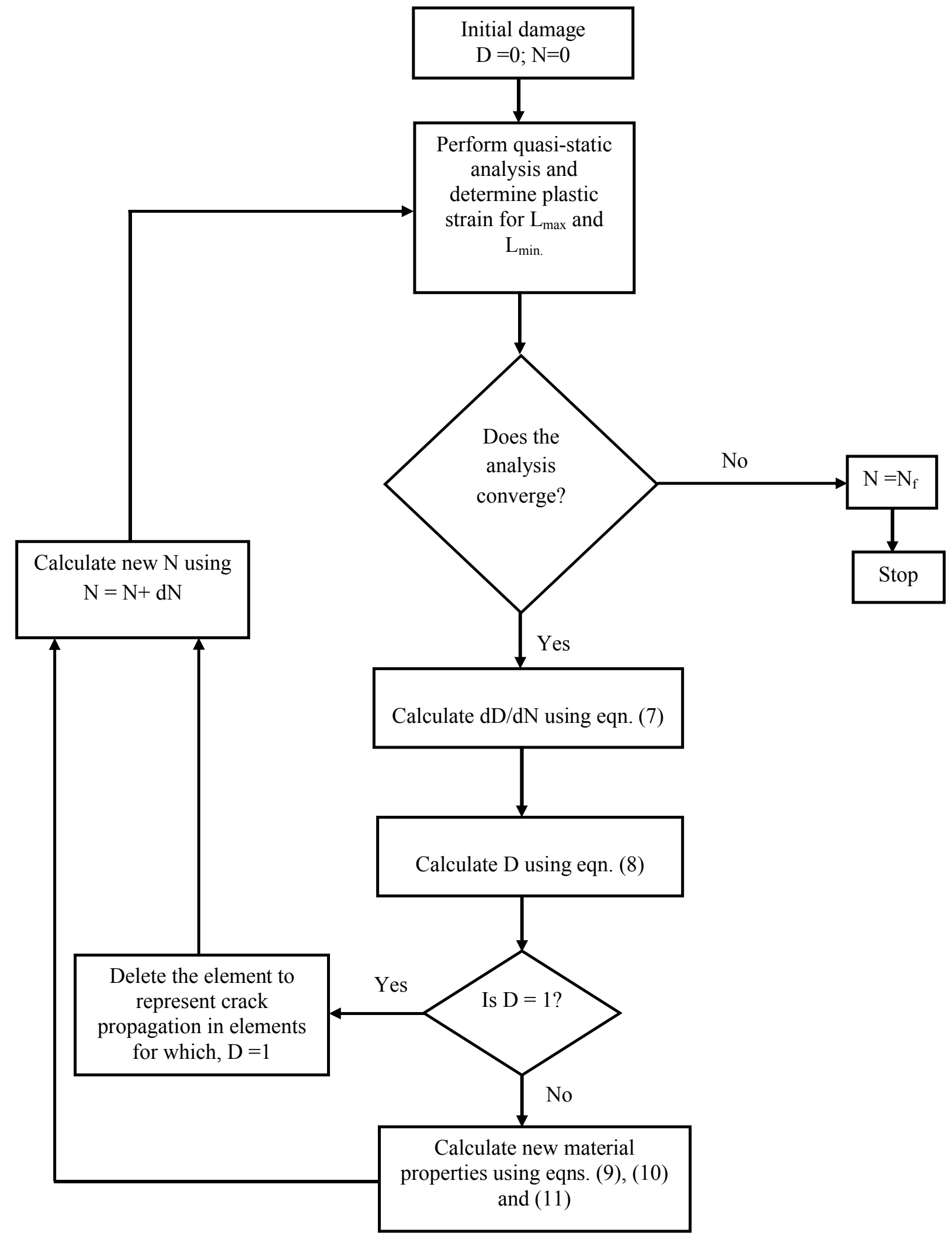

Fig. 10. Algorithm DM based prediction for VAF loading. 


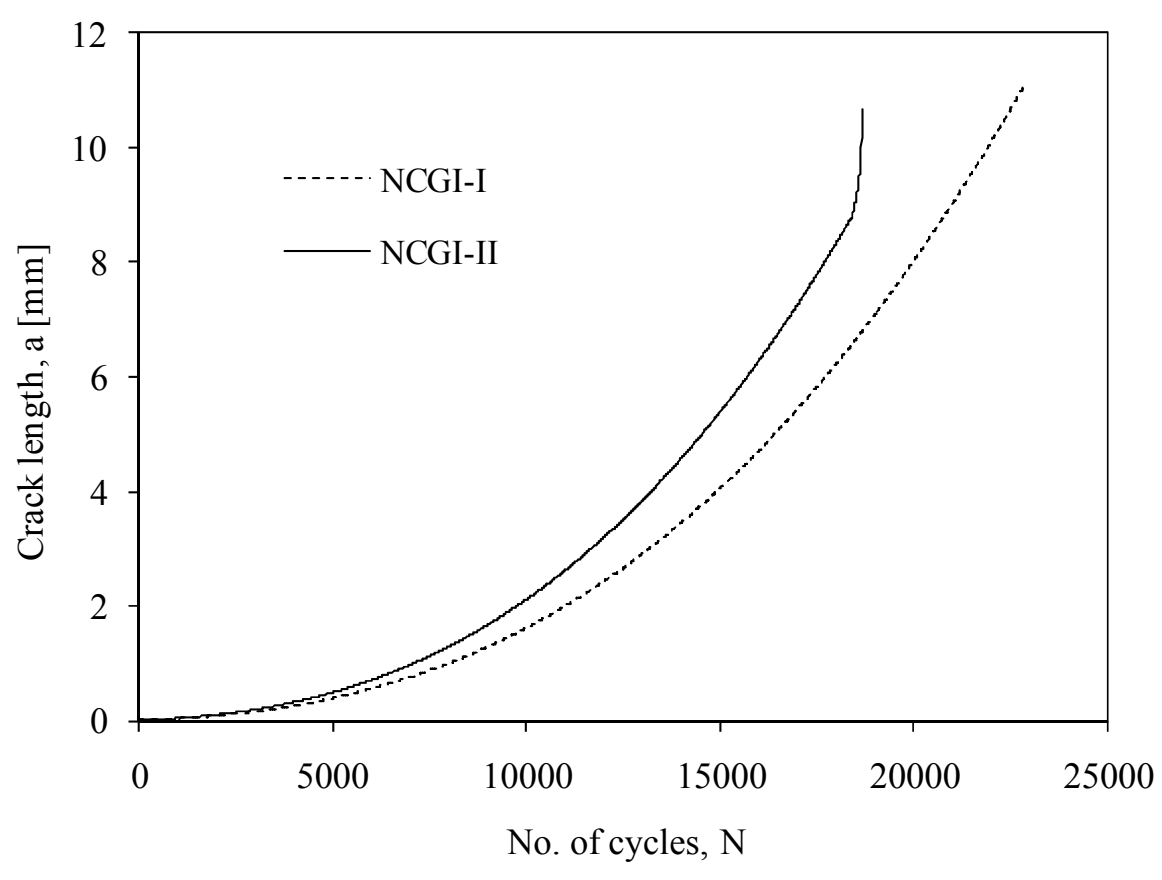

(a)

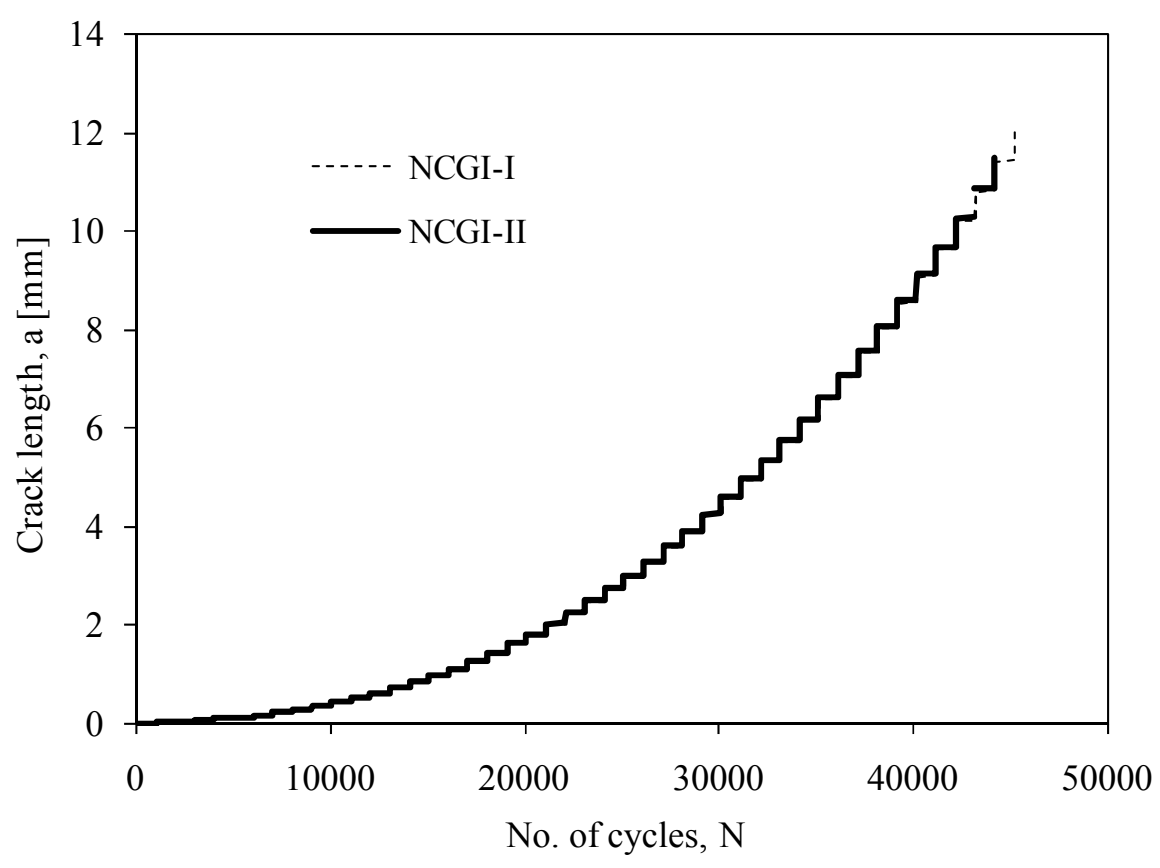

(b)

Fig. 11. Crack growth comparison between NCGI-I and II approaches for (a) Type A spectrum and (b) for Type B spectrum. 


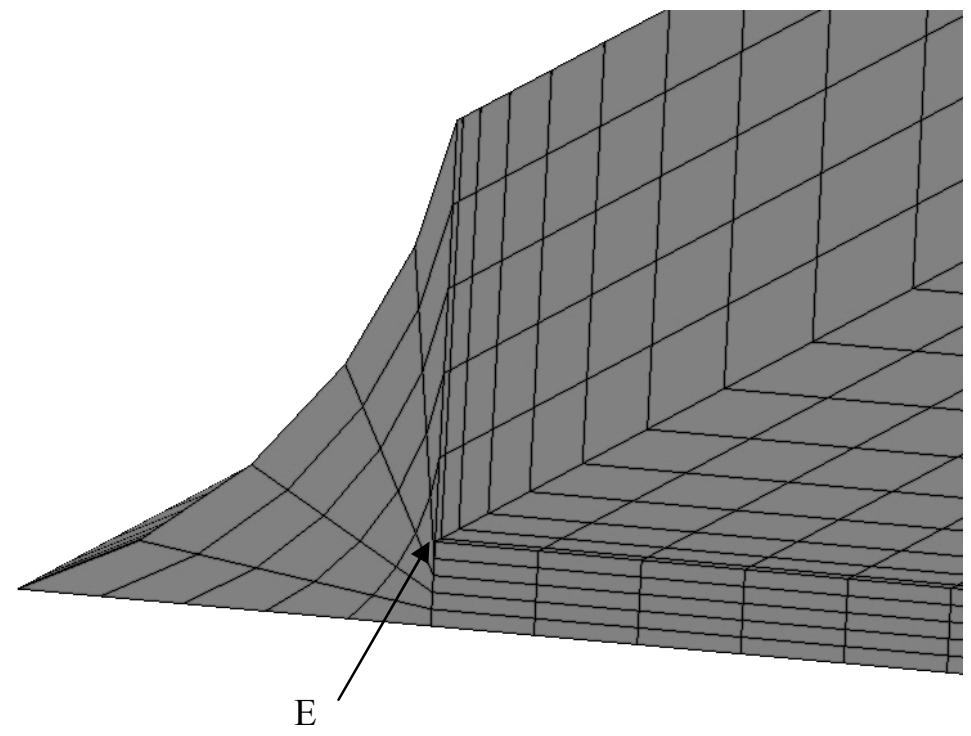

(a)

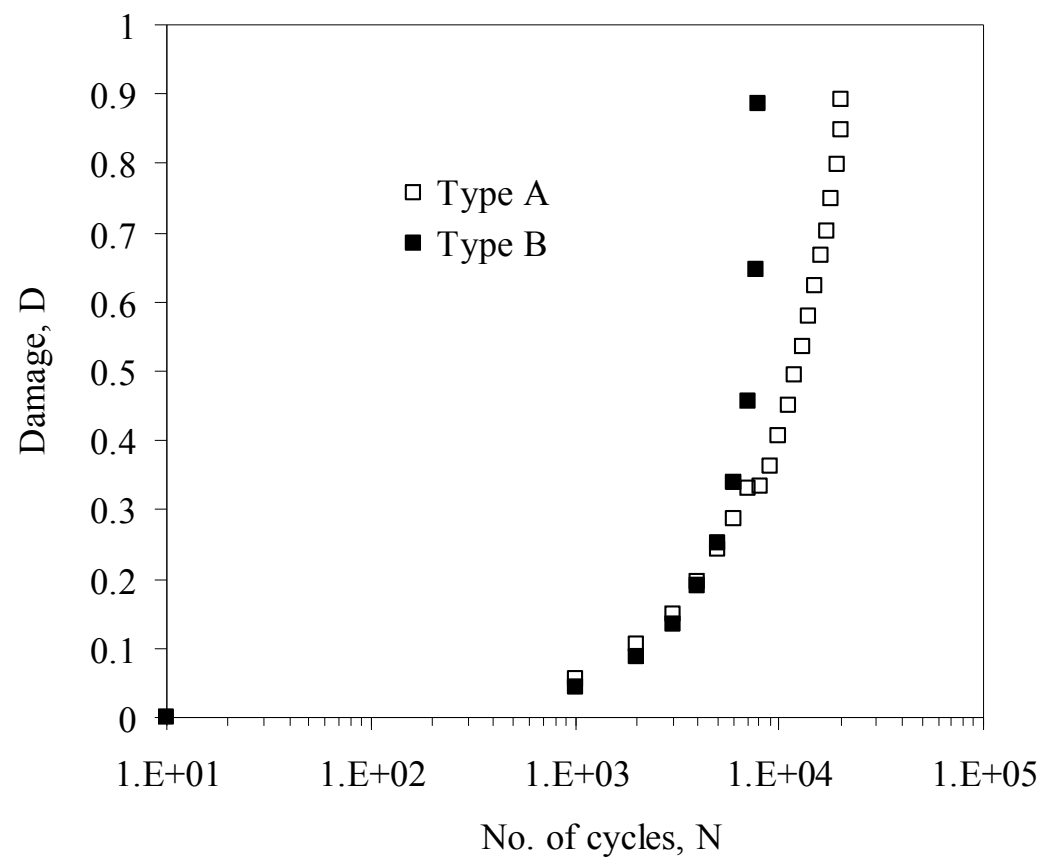

(b)

Fig. 12. (a) Element $\mathrm{E}$, in the embedded corner region and (b) damage in element $\mathrm{E}$ prior to initial cracking as a function of cycles for $\mathrm{L}_{\max 1}=6.5 \mathrm{kN}$. 


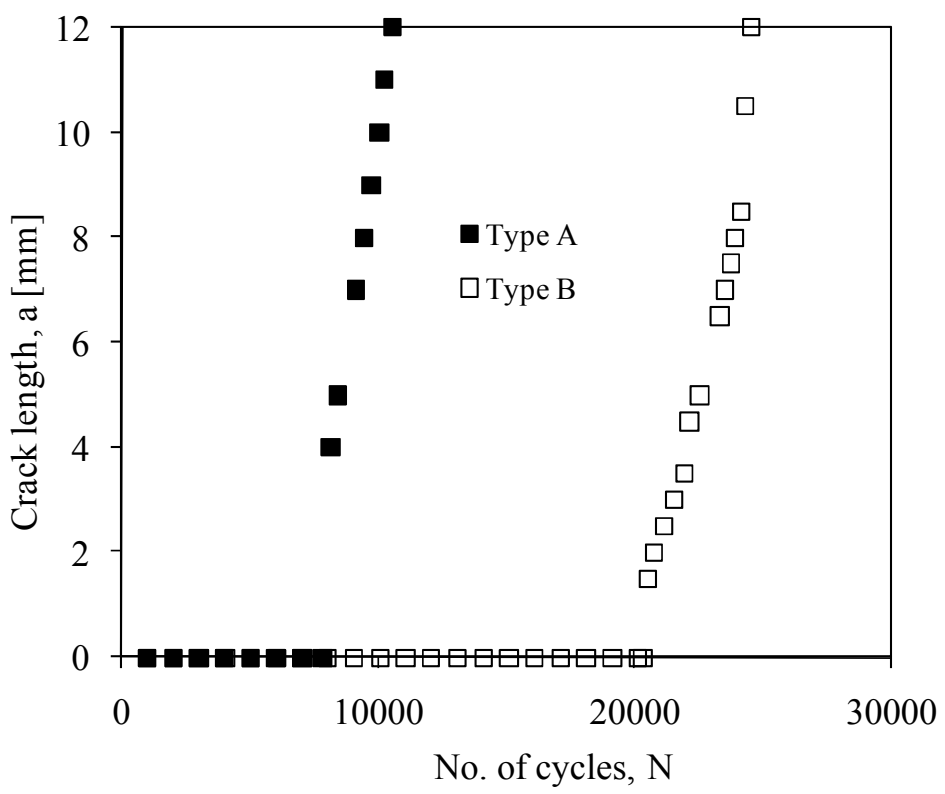

Fig.13. Crack growth for Type A and B spectra for $\mathrm{L}_{\max 1}=6.5 \mathrm{kN}$. 


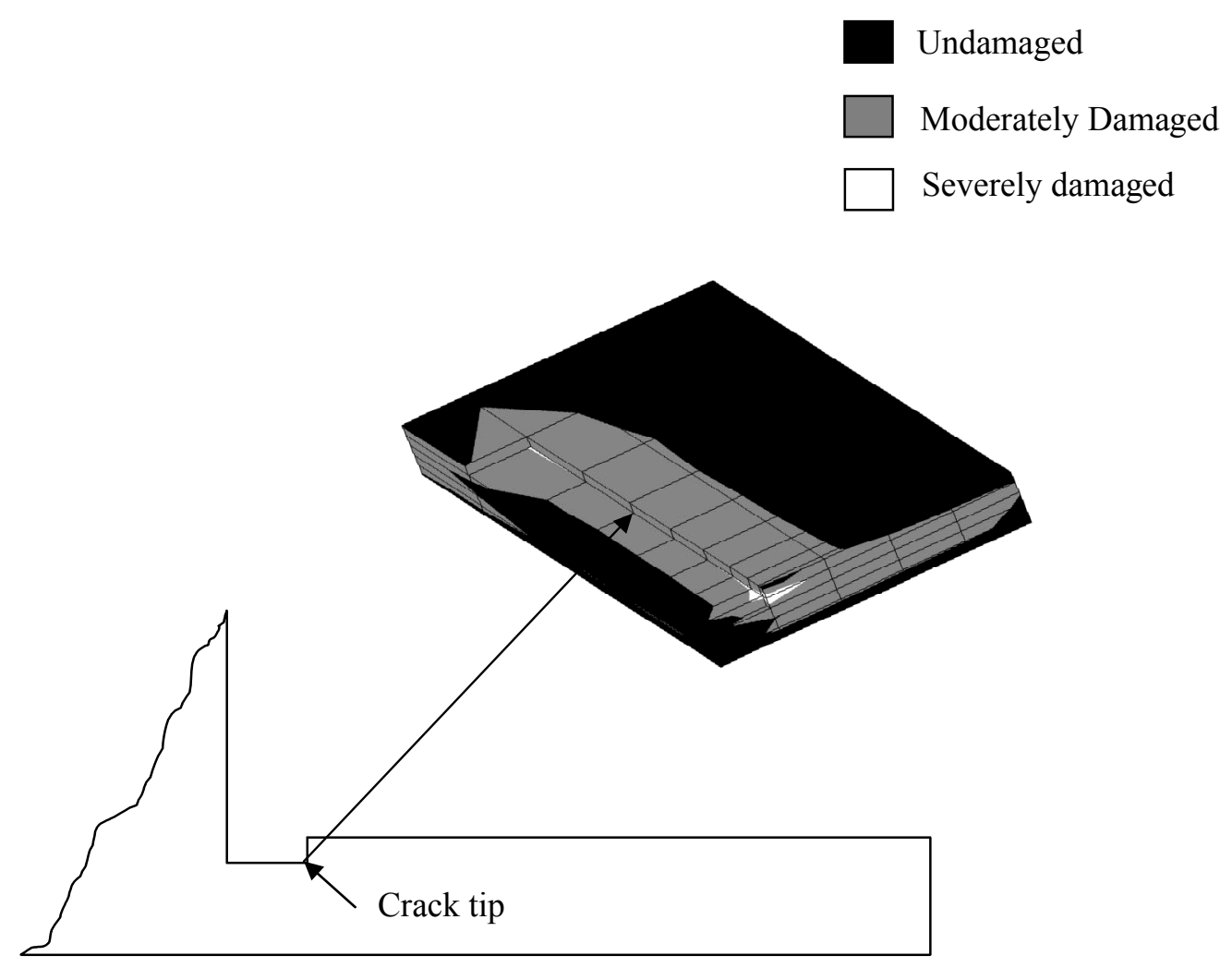

Fig.14. Process zones ahead of crack tip obtained for $\mathrm{L}_{\max 1}=6.5 \mathrm{kN}$ for Type A spectrum after 1000 cycles. 


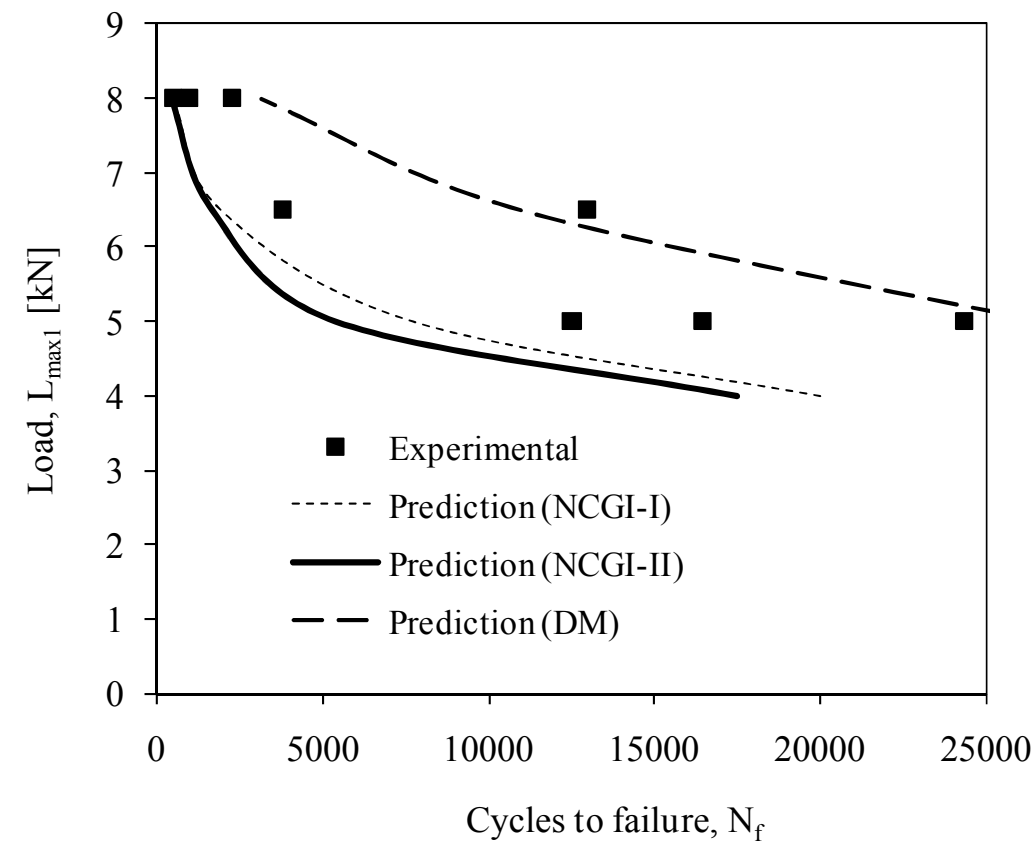

(a)

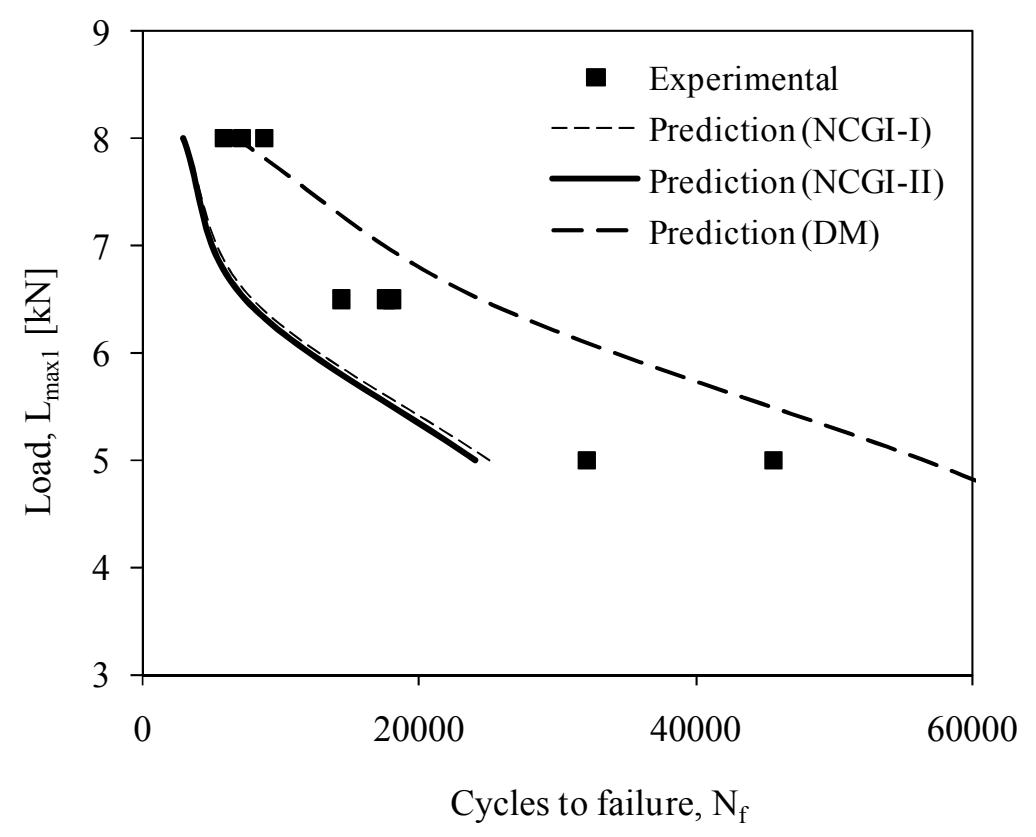

(b)

Fig. 15. Comparison of predicted fatigue lifetimes for FM based and DM based approaches for (a) Type A and (b) Type B spectra. 